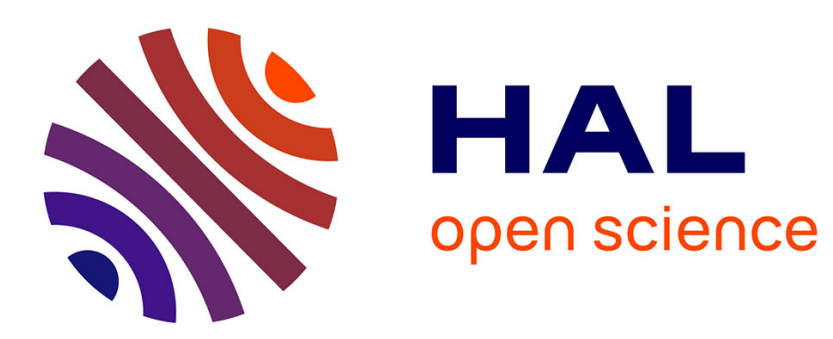

\title{
Structurally Precise Dichalcogenolate-Protected Copper and Silver Superatomic Nanoclusters and Their Alloys
}

Sachil Sharma, Kiran Kumarvarma Chakrahari, Jean-Yves Saillard, C W Liu

\section{To cite this version:}

Sachil Sharma, Kiran Kumarvarma Chakrahari, Jean-Yves Saillard, C W Liu. Structurally Precise Dichalcogenolate-Protected Copper and Silver Superatomic Nanoclusters and Their Alloys. Accounts of Chemical Research, 2018, 51 (10), pp.2475-2483. 10.1021/acs.accounts.8b00349 . hal-01903309

HAL Id: hal-01903309

https://hal-univ-rennes1.archives-ouvertes.fr/hal-01903309

Submitted on 9 Nov 2018

HAL is a multi-disciplinary open access archive for the deposit and dissemination of scientific research documents, whether they are published or not. The documents may come from teaching and research institutions in France or abroad, or from public or private research centers.
L'archive ouverte pluridisciplinaire HAL, est destinée au dépôt et à la diffusion de documents scientifiques de niveau recherche, publiés ou non, émanant des établissements d'enseignement et de recherche français ou étrangers, des laboratoires publics ou privés. 


\section{Structurally Precise Dichalcogenolate-Protected Copper and Silver Superatomic Nanoclusters and Their Alloys}

Sachil Sharma, ${ }^{\dagger}$ Kiran Kumarvarma Chakrahari, ${ }^{\dagger, 8}$ Jean-Yves Saillard, ${ }^{* *}$ and C. W. Liu* ${ }^{\dagger}$

${ }^{\dagger}$ Department of Chemistry, National Dong Hwa University, Hualien 97401, Taiwan (R.O.C.)

$\$$ Univ Rennes, CNRS, ISCR - UMR 6226, F-35000 Rennes, France

$\S$ Department of Chemistry, SRM Institute of Science and Technology, Kattankulathur 603203, India

\section{CONSPECTUS:}

chalcogenolato silver and copper superatoms are currently a topic of cutting edge research besides the extensively studied $\mathrm{Au}_{\mathrm{n}}(\mathrm{SR})_{\mathrm{m}}$ clusters. The crystal structural analysis is an

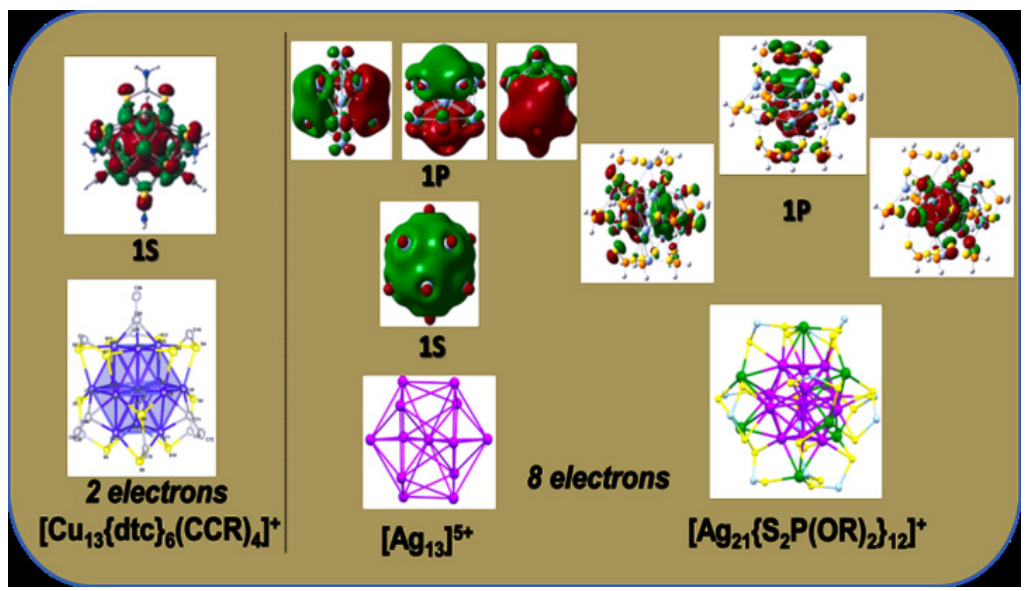
indispensable tool to gain deep insights into the anatomy of these subnanometer clusters. The metal framework and spatial arrangement of the chalcogenolates around the metal core assist in unravelling the structure-property relationship and fundamental mechanistic involved in their fabrication. In this Account, we discuss our contribution towards the development of dichalcogenolato $\mathrm{Ag}$ and $\mathrm{Cu}$ cluster chemistry covering their fabrications and precise molecular structures. Briefly introducing the significance of the single crystal structures of the atomically precise clusters; the novel dichalcogenolated 2-electron superatomic copper and their alloy systems are presented first. The $\left[\mathrm{Cu}_{13}\left\{\mathrm{~S}_{2} \mathrm{CNR}\right\}_{6}\left\{\mathrm{C} \equiv \mathrm{CR}^{\prime}\right\}_{4}\right]^{+}$is so far the first unique copper cluster having $\mathrm{Cu}_{13}$ centred cuboctahedron, which is a miniature of bulk $f c c$. The galvanic exchange of the central $\mathrm{Cu}$ with $\mathrm{Ag} / \mathrm{Au}$ results in a similar anatomy of formed bimetallic $\left[\mathrm{Au} / \mathrm{Ag} @ \mathrm{Cu}_{12}\left(\mathrm{~S}_{2} \mathrm{CN}^{n} \mathrm{Bu}_{2}\right)_{6}(\mathrm{C} \equiv \mathrm{CPh})_{4}\right]\left[\mathrm{CuCl}_{2}\right]$ species. This is unique in a sense that other contemporary $\mathrm{M}_{13}$ cores in group 11 superatomic chemistry are compact icosahedra. The central doping of $\mathrm{Ag}$ or $\mathrm{Au}$ significantly affects the physiochemical properties of the bimetallic $\mathrm{Cu}$ rich clusters. It is manifested in the dramatic quantum 
yield enhancement of the doped species $\left[\mathrm{Au} @ \mathrm{Cu}_{12}\left(\mathrm{~S}_{2} \mathrm{CN}^{n} \mathrm{Bu}_{2}\right)_{6}(\mathrm{C} \equiv \mathrm{CPh})_{4}\right]^{+}$with a value of 0.59 at 77 $\mathrm{K}$ in 2-MeTHF.

In the second part, the novel eight-electron dithiophosphate- and diselenophosphate-protected silver systems are presented. A completely different type of architecture was revealed for the first time from the successful structural determination of $\left[\mathrm{Ag}_{21}\left\{\mathrm{~S}_{2} \mathrm{P}\left(\mathrm{O}^{\mathrm{i}} \mathrm{Pr}\right)_{2}\right\}_{12}\right]^{+}, \quad\left[\mathrm{Ag}_{20}\left\{\mathrm{~S} \mathrm{~S}_{2} \mathrm{P}\left(\mathrm{O}^{\mathrm{i}} \mathrm{Pr}\right)_{2}\right\}_{12}\right]$ and $\left[\mathrm{Au} @ \mathrm{Ag}_{19}\left\{\mathrm{~S}_{2} \mathrm{P}(\mathrm{OPr})_{2}\right\}_{12}\right]$. They exhibit a non-hollow $\mathrm{M}_{13}\left(\mathrm{Ag}\right.$ or $\left.\mathrm{AuAg}_{12}\right)$ icosahedron, capped by 8 and $7 \mathrm{Ag}$ atoms in the former and latter two species, respectively. The overall metal core units are protected by 12 dithiophosphate ligands and the metal-ligand interface structure was found to be quite different from that of $\mathrm{Au}_{\mathrm{n}}(\mathrm{SR})_{\mathrm{m}}$. Notably, the $\left[\mathrm{Ag}_{20}\left\{\mathrm{~S}_{2} \mathrm{P}\left(\mathrm{O}^{\mathrm{i}} \mathrm{Pr}\right)\right\}_{12}\right]$ cluster provides the first structural evidence of silver superatom with a chiral metallic core. This chirality arises through the simple removal of one of capping $\mathrm{Ag}^{+}$cation of $\left[\mathrm{Ag}_{21}\left\{\mathrm{~S}_{2} \mathrm{P}\left(\mathrm{O}^{\mathrm{i}} \mathrm{Pr}\right)_{2}\right\}_{12}\right]^{+}$present on its $C_{3}$ axis. Further, the effects of the ligand exchange on the structures of $\left[\mathrm{Ag}_{20}\left\{\mathrm{Se}_{2} \mathrm{P}\left(\mathrm{O}^{\mathrm{i}} \mathrm{Pr}\right)_{2}\right\}_{12}\right],\left[\mathrm{Ag}_{21}\left\{\mathrm{Se} \mathrm{C}_{2} \mathrm{P}(\mathrm{OEt})_{2}\right\}_{12}\right]^{+}$and $\left[\mathrm{AuAg}_{20}\left\{\mathrm{Se}_{2} \mathrm{P}(\mathrm{OEt})_{2}\right\}_{12}\right]^{+}$are studied extensively. The structure of the former species is similar to its dithiophosphate counterpart ( $C_{3}$ symmetry). The latter two ( $T$ symmetry) differ in the arrangement of 8 capping $\mathrm{Ag}$ atoms, as they form a cube engraving the $\mathrm{Ag}_{13}\left(\mathrm{AuAg}_{12}\right)$ icosahedron. The blue shifts in absorption spectra and photoluminescence further indicate the strong influence of the central Au atom in the doped clusters. In the last, the first paradigm of unusual heteroatom doping induced sizestructure transformation is discussed by presenting the case of formation of $\left[\mathrm{Au}_{3} \mathrm{Ag}_{18}\left\{\mathrm{Se}_{2} \mathrm{P}\left(\mathrm{O}^{\mathrm{i}} \mathrm{Pr}\right)_{2}\right\}_{12}\right]^{+}$ upon Au doping into $\left[\mathrm{Ag}_{20}\left\{\mathrm{Se}_{2} \mathrm{P}\left(\mathrm{O}^{\mathrm{i}} \mathrm{Pr}\right)_{2}\right\}_{12}\right]^{0}$. Finally, before concluding this Account, we discuss the possibility of many unique structural isomers with different physical properties for the aforementioned $\mathrm{Ag}$ superatoms which need to be explored extensively in future.

\section{INTRODUCTION}

The chalcogenolate-protected noble metals clusters and their alloys are currently the subjects of an immense scientific interest. ${ }^{1-3}$ On one hand, their properties tend to prefigure that of their large nanoparticle counterparts, but on the other hand, they retain their molecular characters such as featured absorption spectra, ${ }^{2}$ photoluminescence, ${ }^{3}$ redox behaviour ${ }^{4}$ and chirality. ${ }^{5}$ Since most of the 
molecular properties are strongly governed by their structures, the structural determination of ligand protected metal clusters is vital to unravelling their structure-property correlations and the reaction mechanistic. X-ray diffraction is by far the best technique for exploring cluster structural intimacy and, inter alia, the metal-ligand interfaces. However, for X-ray diffraction, it is essential to grow suitable single crystals. Fortunately, owing to their sub-nanometer size, atom-precise nature and high stability, small metal nanoclusters capped by rigid ligands can be easily crystallized. This feature makes such nanoclusters a structural paradigm for the study of clusters and nanoparticles of bigger size.

Beside of the extensive progression of the thiol-capped Au nanocluster chemistry, those of the other Group 11 metals, $\mathrm{Cu}$ and $\mathrm{Ag}$, are much less developed. ${ }^{6-8}$ Structurally characterized copper superatomic nanoclusters are scarce. ${ }^{8}$ Although the chemistry of chalcogenolated Ag nanoclusters is currently a highly sought topic, there are still relatively few crystal structures reported for chalcogenolate protected Ag nanoclusters. ${ }^{6-7}$ In this account, we highlight our recent research findings on the precise structures of dichalcogenolate-capped closed-shell $\mathrm{Cu}$ and $\mathrm{Ag}$ superatoms in the context of the contemporary research in this field. Dichalcogenolate ligands, such as dichalcogenophosphates $\left(\left[\mathrm{E}_{2} \mathrm{P}(\mathrm{OR})_{2}\right]^{-}\right)\left(\mathrm{E}=\mathrm{S}\right.$, Se) or dithiocarbamates $\left(\left[\mathrm{S}_{2} \mathrm{CNR}_{2}\right]^{-}\right)$are formally monoanions like mono-chalogenolates (ER'), but they bear two coordinating $\mathrm{E}$ atoms. Thus, besides of the fact that a dichalcogenolate ligand is less bulky than two monochalcogenolates, the demand of an isolable, stable molecule for approaching charge neutrality as much as possible will be satisfied differently. To reach molecular neutrality, a given closed-shell $\mathrm{M}_{\mathrm{n}}{ }^{\mathrm{x}}$ superatomic kernel needs to be passivated by $\mathrm{x}$ mono- or di-chalcogenolates. However, dichalcogenolates need twice metal coordinating sites more than mono-chalcogenolates. Therefore, even if supplementary outer M(I) ions and other ligands are also present in the protecting shell, the dichalcogenolate clusters are expected to have different composition and topology that their mono-chalcogenolate counterparts.

\section{DICHALCOGENOLATE-PROTECTED COPPER AND COPPER-RICH SUPERATOMS}


As far as we know, only four homometallic copper superatoms have been structurally characterized till now. They are all characterized by the same number of jellium electrons (je), namely 2 , which is the lowest closed-shell "magic" electron count that superatom can have, ${ }^{9-10}$ as defined within the framework of the spherical jellium approximation ( $1 \mathrm{~S}^{2}$ configuration). In the case of copper, the je electrons are the $4 \mathrm{~s}$ electrons resulting from the average metal oxidation state (between $+\mathrm{I}$ and 0 ). $3 \mathrm{~d}$ electrons are not considered, since in a first approximation they remain non-bonding. These four 2-je species are $\left[\mathrm{Cu}_{25} \mathrm{H}_{22}\left(\mathrm{PPh}_{3}\right)_{12}\right]^{+}(\mathbf{1}),{ }^{11}\left[\mathrm{Cu}_{29} \mathrm{Cl}_{4} \mathrm{H}_{22}\left(\mathrm{Ph}_{2} \text { phen }\right)_{12}\right]^{+}(\mathbf{2}),{ }^{12}\left[\mathrm{Cu}_{20}(\mathrm{CCPh})_{12}(\mathrm{OAc})_{6}\right](\mathbf{3})^{13}$ and $\left[\mathrm{Cu}_{13}\left\{\mathrm{~S}_{2} \mathrm{CN}^{n} \mathrm{Bu}_{2}\right\}_{6}(\text { acetylide })_{4}\right]^{+}$(4). ${ }^{14}$ A few chalcogenolate-protected copper-rich bimetallic superatoms are also known, namely the 2-je $\left[\mathrm{M} @ \mathrm{Cu}_{12}(\mathrm{dtc} / \mathrm{dtp})_{6}(\mathrm{C} \equiv \mathrm{CPh})_{4}\right]^{+},(\mathrm{dtc}=$ dithiocarbamate, $\mathrm{dtp}=$ dithiophosphate; $\mathrm{M}=\mathrm{Ag}, \mathrm{Au})^{15}$ the 2-je $\mathrm{Au}_{2} \mathrm{Cu}_{6}\left(\mathrm{PPh}_{2} \mathrm{Py}\right)_{2}(\mathrm{AdmSH})_{6}(\mathrm{AdmSH}=$ adamantanethiol $),{ }^{16}$ the $18-j e$ series $\left[\mathrm{Au}_{12+\mathrm{n}} \mathrm{Cu}_{32}(\mathrm{SR})_{30+\mathrm{n}}\right]^{4-},{ }^{17}$ the $20-j e\left[\mathrm{Ag}_{28} \mathrm{Cu}_{12}(\mathrm{SR})_{24}\right]^{4-} \cdot{ }^{18}$ Apart from the previous species, the recently reported $67-j e$ cluster $\left[\mathrm{Cu}_{43} \mathrm{Al}_{12} \mathrm{Cp}^{*}{ }_{12}\right]{ }^{19}$ having a 55 -atom core and a "non-magic" electron count associated with an open-shell configuration, is a proof that isolation of large ligand-protected copper or copper-rich superatoms is possible, as predicted by DFT calculation. $^{20}$

\section{Dichalcogenolato 2-je superatomic copper nanoclusters and their alloys:}

Previously our group demonstrated that polyhydrido copper(I) clusters supported by dichalcogenolates are valuable intermediates en route to the formation of copper( 0$)$ nanoparticles fabricated by chemical reduction methods (Scheme 1). ${ }^{21}$ Along this route, it is natural to assume that copper hydride superatoms with intermediate $\mathrm{Cu}$ average oxidation states should be present. Whereas we have not been able to isolate such species, the phosphine-protected compound $\left[\mathrm{Cu}_{25} \mathrm{H}_{22}\left(\mathrm{PPh}_{3}\right)_{12}\right]^{+}$ (1) provides the first example of copper hydrides having a partial $\mathrm{Cu}(0)$ oxidation state. ${ }^{11}$ 


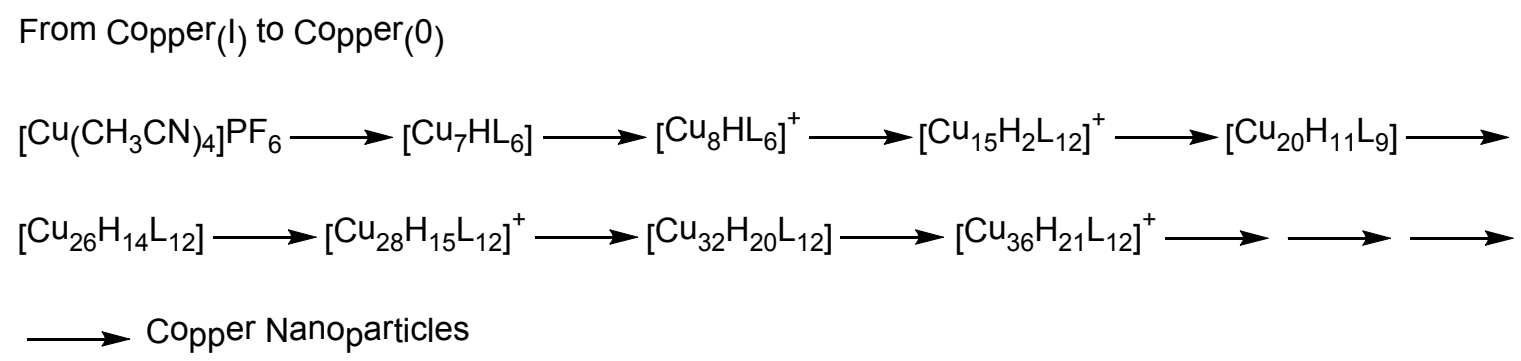

Scheme 1: General mechanisms proposed for the reduction of $\mathrm{Cu}(\mathrm{I})$ and $\mathrm{Ag}(\mathrm{I})$ clusters by $\mathrm{NaBH}_{4}$ in the presence of dichalcogenolate ligands (L), en route to metal nanoparticles.

In fact, the use of additional non-chalcolenolate ligands appears to be necessary. Clusters $\mathbf{1}$ and $\mathbf{3}$ were isolated by the reduction of $\mathrm{Cu}(\mathrm{I})$ salts with diphenylsilane in the presence of external ligands, ${ }^{11,13}$ while 2 was synthesized upon controlled growth from $1 .{ }^{12}$ On our side, we prepared cluster 4 by reacting $\mathrm{Cu}(\mathrm{I})$ polyhydrides with terminal alkynes. ${ }^{14}$ For example, the dtc series $\left[\mathrm{Cu}_{13}\left\{\mathrm{~S}_{2} \mathrm{CNR}_{2}\right\}_{6}\left\{\mathrm{C} \equiv \mathrm{CR}^{\prime}\right\}_{4}\right]\left(\mathrm{PF}_{6}\right)$, 4a-e $\left(\mathbf{a}: \mathrm{R}={ }^{n} \mathrm{Bu}, \mathrm{R}^{\prime}=\mathrm{C}_{2} \mathrm{Ph} ; \mathbf{b}: \mathrm{R}={ }^{n} \mathrm{Bu}, \mathrm{R}^{\prime}=\mathrm{CO}_{2} \mathrm{Et} ; \mathbf{c}: \mathrm{R}={ }^{i} \mathrm{Pr}, \mathrm{R}^{\prime}\right.$ $\left.=\mathrm{CO}_{2} \mathrm{Et} ; \mathbf{d}: \mathrm{R}={ }^{n} \mathrm{Pr}, \mathrm{R}^{\prime}=3,5-\left(\mathrm{CF}_{3}\right)_{2} \mathrm{C}_{6} \mathrm{H}_{3} ; \mathbf{e}: \mathrm{R}={ }^{n} \mathrm{Bu}, \mathrm{R}^{\prime}=\mathrm{CO}_{2} \mathrm{Me}\right)^{14,15}$ were formed via the reaction of terminal alkynes with the $\mathrm{Cu}(\mathrm{I})$ polyhydrido clusters, namely $\left[\mathrm{Cu}_{28} \mathrm{H}_{15}\left(\mathrm{~S}_{2} \mathrm{CNR}_{2}\right)_{12}\right]^{+}{ }^{22}$ Clusters 4 a-e are the so far unique structurally characterized copper clusters having a $\mathrm{Cu}_{13}$ centered cuboctahedral arrangement, a miniature of the bulk copper $f c c$ structure. Indeed, the most frequent $\mathrm{M}_{13}$ kernel motif encountered in Group 11 superatom chemistry is the more compact centered icosahedron. For instance, Hayton's clusters 1-2 can be viewed as made of a centered icosahedron $\mathrm{Cu}_{13}$ of formal charge +11 (i.e. containing the two jellium electrons) protected by an outer sphere made of peripheral $\mathrm{Cu}(\mathrm{I})$ ions, phosphines and/or anionic ligands. ${ }^{11-12}$ In the case of clusters 4, four among the eight triangular faces of the cuboctahedron are capped by acetylide groups in a $\mu_{3}$ fashion and each of the six square faces is bridged by a dithiolate ligand in a $\left(\mu_{2}, \mu_{2}\right)$ fashion (Figure 1). Cu K-edge XANES experiments show that clusters $4,{ }^{23}$ similarly as for $\mathbf{1 - 3},{ }^{11-13}$ feature an edge energy intermediate between those of $\mathrm{Cu}(0)$ and $\mathrm{Cu}(\mathrm{I})$. This is fully consistent with DFT calculations which lead to a 
description of $\mathbf{4}$ as made of a 2-je superatomic core $\left[\mathrm{Cu}_{13}\right]^{11+}$ core passivated by ten monoanionic ligands, with an $a_{1}$ HOMO containing two $1 \mathrm{~S}$ jellium electrons. ${ }^{14}$ The localization of these two electrons on the central copper is found to be larger than that on the icosahedral positions. This leads to a limit (somewhat exaggerated) view of a $\mathrm{Cu}(-\mathrm{I})$ anion encapsulated in a $\left[\mathrm{Cu}_{12}\right]^{12+}$ cage.

The presence of a $\mathrm{Cu}$ atom in a low oxidation state at the center of clusters $\mathbf{4}$ makes the alloy formation feasible via a templated galvanic exchange approach as shown in Scheme 2. $\left[\mathrm{Cu} @ \mathrm{Cu}_{12}\left(\mathrm{~S}_{2} \mathrm{CN}^{\mathrm{n}} \mathrm{Bu}_{2}\right)_{6}(\mathrm{C} \equiv \mathrm{CPh})_{4}\right]\left[\mathrm{CuCl}_{2}\right](\mathbf{4 a})$ was used as a template to generate compositionally uniform Cu-rich clusters $\left[\mathrm{M} @ \mathrm{Cu}_{12}\left(\mathrm{~S}_{2} \mathrm{CN}^{\mathrm{n}} \mathrm{Bu}_{2}\right)_{6}(\mathrm{C} \equiv \mathrm{CPh})_{4}\right]\left[\mathrm{CuCl}_{2}\right]$, where $\mathrm{M}=\mathrm{Ag}(\mathbf{5}), \mathrm{Au}(\mathbf{6}) .{ }^{15}$ The anatomies of clusters 5-6 are very similar to that of 4 (Figure 1). The doped Ag and Au atoms occupy the centre of the 13-atom cuboctahedral core, providing unique examples of heteroatom-doping at the single atom level. Both $\mathrm{Ag}$ and $\mathrm{Au}$ doping resulted in significant changes in physiochemical properties. For example, silver doping decreases cluster stability, whereas gold doping results in a higher stability. Subsequently, 6 could be also isolated via a one-pot reaction, from which the new dtp species, $\quad\left[\mathrm{Au} @ \mathrm{Cu}_{12}\left(\mathrm{~S}_{2} \mathrm{P}\left(\mathrm{O}^{i} \mathrm{Pr}\right)_{2}\right)_{6}(\mathrm{C} \equiv \mathrm{CPh})_{4}\right]^{+} \quad\left(6^{\prime}\right)$, were $\quad$ synthesized starting from $\left[\mathrm{Cu}_{32} \mathrm{H}_{20}\left\{\mathrm{~S}_{2} \mathrm{P}\left(\mathrm{O}^{\mathrm{i}} \mathrm{Pr}\right)_{2}\right\}_{12}\right]($ Scheme 2$){ }^{24}$

$$
\begin{aligned}
& \underset{4}{\left[\mathrm{Cu}_{13}\left(\mathrm{~S}_{2} \mathrm{CN}^{n} \mathrm{Bu}_{2}\right)_{6}\left(\mathrm{C}^{\circ} \mathrm{CPh}\right)^{4}\right]^{+}} \frac{\mathrm{M}^{+}, \mathrm{THF}}{-5^{\circ} \mathrm{C}, 12 \mathrm{~h}}\left[\mathrm{M} @ \mathrm{Cu}_{12}\left(\mathrm{~S}_{2} \mathrm{CN}^{n} \mathrm{Bu}_{2}\right)_{6}(\mathrm{C} \equiv \mathrm{CPh})^{4}\right]^{+}
\end{aligned}
$$

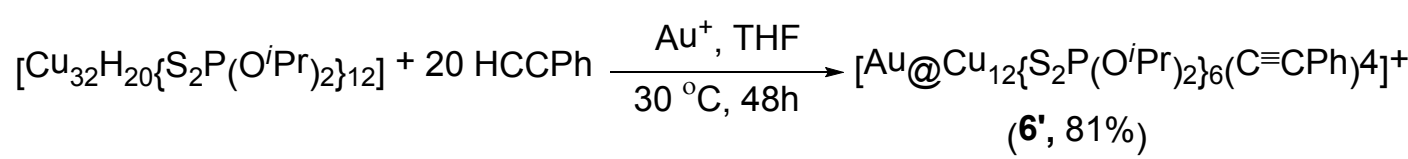

Scheme 2. Synthesis of compounds $\mathbf{5}, \mathbf{6}$, and $\mathbf{6}$ '.

A dramatic enhancement of both emission intensity and quantum yield was observed in gold-copper alloys $\left(\mathbf{6}, \mathbf{6}^{\prime}\right)$ by comparison with cluster 4 (Figure 2). Cluster $\mathbf{6}$ displays yellow emission in both solid and solution states even at ambient temperature. Compared to 6 its dtp analogue 6' displays even 
more enhanced luminescence. The quantum yield value of 6 at $77 \mathrm{~K}$ in MeTHF is 0.59 , whereas for $\mathbf{6}$ ' it is 0.37 at $298 \mathrm{~K}$.

\section{CHALCOGENOLATE-PROTECTED SILVER AND SILVER-RICH SUPERATOMS}

Till the end of June 2018 the crystals structures of 23 chalcogenolate protected closed shell silver superatoms have been reported, viz $\mathrm{Ag}_{14}\left(\mathrm{SC}_{6} \mathrm{H}_{3} \mathrm{~F}_{2}\right)_{12}\left(\mathrm{PPh}_{3}\right)_{8}{ }^{25} \quad \mathrm{Ag}_{16}(\mathrm{DPPE})_{4}\left(\mathrm{SC}_{6} \mathrm{H}_{3} \mathrm{~F}_{2}\right)_{14}{ }^{26}{ }^{26}$ $\left[\mathrm{Ag}_{25}\left(\mathrm{SPhMe}_{2}\right)_{18}\right]^{-27} \quad\left[\mathrm{Ag}_{24} \mathrm{Au}\left(\mathrm{SPhMe}_{2}\right)_{18}\right]^{-28}, \quad\left[\mathrm{Ag}_{44}(\mathrm{SR})_{30}\right]^{4-}\left(\mathrm{SR}=p-\mathrm{MBA} / \mathrm{SPhF}_{2}\right),{ }^{29-30}$ $\left[\mathrm{Au}_{12} \mathrm{Ag}_{32}\left(\mathrm{SPhF}_{2}\right)_{30}\right]^{4-},{ }^{30} \quad\left[\mathrm{MAg}_{24}\left(2,4-\mathrm{SPhCl}_{2}\right)_{18}\right]^{2-}(\mathrm{M}=\mathrm{Pd} / \mathrm{Pt})^{31} \quad\left[\mathrm{Au}_{9} \mathrm{Ag}_{12}(\mathrm{SR})_{4}(\mathrm{dppm})_{6} \mathrm{X}_{6}\right]^{3+}$ $\left(\mathrm{SR}=\mathrm{SAdm} / \mathrm{S}-{ }^{\mathrm{t}} \mathrm{Bu}\right.$ and $\left.\mathrm{X}=\mathrm{Cl}^{-} / \mathrm{Br}^{-}\right),{ }^{32} \quad\left[\mathrm{Ag}_{21}\left\{\mathrm{~S}_{2} \mathrm{P}\left(\mathrm{O}^{\mathrm{i}} \mathrm{Pr}\right)_{2}\right\}_{12}\right]^{+33}, \quad\left[\mathrm{Ag}_{20}\left\{\mathrm{~S}_{2} \mathrm{P}(\mathrm{OR})_{2}\right\}_{12}\right] \quad\left(\mathrm{R}=\mathrm{Pr} /{ }^{i} \mathrm{Pr}\right),{ }^{34}$ $\left[\mathrm{Au} @ \mathrm{Ag}_{19}\left\{\mathrm{~S}_{2} \mathrm{P}(\mathrm{OPr})_{2}\right\}_{12}\right],{ }^{35} \quad \mathrm{Ag}_{29}(\mathrm{BDT})_{12}(\mathrm{TPP})_{4},{ }^{36} \quad\left[\mathrm{Pt}_{1} \mathrm{Au}_{6.4} \mathrm{Ag}_{17.6}\left(\mathrm{SPhMe}_{2}\right)_{18}\right],{ }^{37}$ $\left.\left[\mathrm{Pt}_{1} \mathrm{Ag}_{28}(\mathrm{BDT})_{18}\left(\mathrm{PPh}_{3}\right)_{4}\right]^{4-38} \quad\left[\mathrm{PtAg}_{28}(\mathrm{~S}-\mathrm{Adm})_{18}\left(\mathrm{PPh}_{3}\right)_{4}\right]^{2+}, 39 \quad\left[\mathrm{Ag}_{21}\left\{\mathrm{Se}_{2} \mathrm{P}(\mathrm{OEt})_{2}\right\}\right\}_{12}\right]^{+40}$, $\left[\mathrm{Ag}_{20}\left\{\mathrm{Se}_{2} \mathrm{P}\left(\mathrm{O}^{\mathrm{i}} \mathrm{Pr}\right)_{2}\right\}_{12}\right],{ }^{40} \quad\left[\mathrm{AuAg}_{20}\left\{\mathrm{Se}_{2} \mathrm{P}(\mathrm{OR})_{2}\right\}_{12}\right]^{+} \quad\left(\mathrm{R}=\mathrm{Et} /{ }^{\mathrm{i}} \mathrm{Pr}\right),{ }^{40-41} \quad\left[\mathrm{Au}_{3} \mathrm{Ag}_{18}\left\{\mathrm{Se} \mathrm{S}_{2} \mathrm{P}\left(\mathrm{O}{ }^{\mathrm{i}} \mathrm{Pr}\right)_{2}\right\}_{12}\right]^{+41}$, $\mathrm{Au}_{4} \mathrm{Ag}_{13}(\mathrm{DPPM})_{3}\left(\mathrm{SPhMe}_{2}\right)_{9},{ }^{42} \quad \mathrm{Ag}_{26} \mathrm{Pt}(2-\mathrm{EBT})_{18}\left(\mathrm{PPh}_{3}\right)_{6},{ }^{43} \quad \mathrm{Au}_{5.6} \mathrm{Ag}_{19.4}\left(\mathrm{SC}_{6} \mathrm{H}_{11}\right)_{18},{ }^{44} \quad$ and $\mathrm{Au}_{4.55} \mathrm{Ag}_{20.45}\left(\mathrm{SC}_{6} \mathrm{H}_{11}\right)_{18 .}{ }^{45}$ The structural chemistry of $\mathrm{Ag}$ and Ag-rich dithiophosphate- (dtp) and diselenophosphate- (dsep) protected superatoms is presented below.

\subsection{8-je dithiophosphate protected Silver Superatoms}

In 2013, the first successful crystallization of silver superatoms, namely the 2-je clusters $\mathrm{Ag}_{14}\left(\mathrm{SC}_{6} \mathrm{H}_{3} \mathrm{~F}_{2}\right)_{12}\left(\mathrm{PPh}_{3}\right)_{8}{ }^{25}$ and $\mathrm{Ag}_{16}(\mathrm{DPPE})_{4}\left(\mathrm{SC}_{6} \mathrm{H}_{3} \mathrm{~F}_{2}\right)_{14}{ }^{26}$ revealed a complex nature of the metal-thiol interface structure in $\mathrm{Ag}$ nanoclusters (only $\mathrm{Ag}(5 \mathrm{~s})$ electrons are considered in the je count). Later we found a completely different architecture in a series of 8-je dtp-protected silver clusters such as $\left[\mathrm{Ag}_{21}\left\{\mathrm{~S}_{2} \mathrm{P}\left(\mathrm{O}^{\mathrm{i}} \mathrm{Pr}\right)_{2}\right\}_{12}\right]^{+}(\mathbf{7}),{ }^{33}\left[\mathrm{Ag}_{20}\left\{\mathrm{~S}{ }_{2} \mathrm{P}\left(\mathrm{O}^{\mathrm{i}} \mathrm{Pr}\right)_{2}\right\}_{12}\right](\mathbf{8 a}){ }^{34}$ and $\left[\mathrm{Au} @ \mathrm{Ag}_{19}\left\{\mathrm{~S}_{2} \mathrm{P}\left(\mathrm{O}^{\mathrm{i} P r}\right)_{2}\right\}_{12}\right]$ (9).$^{35}$

3.1.1 $\left[\operatorname{Ag}_{21}\left\{\mathrm{~S}_{2} \mathbf{P}\left(\mathbf{O}^{\mathrm{i}} \mathrm{Pr}\right)_{2}\right\}_{12}\right]^{+}$(7): In keeping abreast of copper hydride chemistry, we thought it should be possible to isolate polyhydrido silver(I) clusters stabilized by chalcogen-donor ligands (Scheme 1). Surprisingly, cluster 7 was isolated by one-phase reduction; that is the reaction of silver(I) salts with dtp ligands in the presence of an excess of $\mathrm{NaBH}_{4}{ }^{33}$ Its structure exhibits an $\mathrm{Ag}_{13}$ centered icosahedral core capped by 8 outer $\mathrm{Ag}$ atoms. The overall $\mathrm{Ag}_{21}$ metal unit is protected by $12 \mathrm{dtp}$ ligands. The 
whole molecule is of ideal $C_{3}$ symmetry, with the 3 -fold axis passing through the centres of two eclipsed triangular faces of the icosahedron, the bare $\mathrm{Ag}_{21}$ unit being close to $D_{3 h}$ symmetry ${ }^{33}$ (Figure 3a). This was the first example of a silver nanocluster containing a non-hollow icosahedral core, distinct from the previously reported empty $\mathrm{Ag}_{12}$ icosahedron present in $\mathrm{M}_{4} \mathrm{Ag}_{44}(\mathrm{SR})_{30}(\mathrm{M}=$ alkali metal). ${ }^{29-30}$ Later, Bakr et al. found a similar type of non-hollow $\mathrm{Ag} @ \mathrm{Ag}_{12}$ icosahedron in $\left[\mathrm{Ag}_{25}\left(\mathrm{SPhMe}_{2}\right)_{18}\right]^{-27}$

Notably, the metal ligand interface topology in 7 is different from that encountered in $\operatorname{Au}_{\mathrm{n}}(\mathrm{SR})_{\mathrm{m}}$ species. $^{46}$ The 12 dtp ligands surround the whole $\mathrm{Ag}_{21}$ core, displaying either trimetallic triconnectivity $\left(\eta^{3}: \mu_{2}, \mu_{1}\right)$ or trimetallic tetraconnectivity $\left(\eta^{3}: \mu_{2}, \mu_{2}\right)$, in the latter case with one long contact (see below). The 8 capping $\mathrm{Ag}$ atoms are all found to display a nearly planar $\mathrm{AgS}_{3}$ coordination mode. Within the icosahedron, the top and bottom triangular faces show an Ag-S coordination mode, while the remaining six icosahedral vertices exhibit $\mathrm{AgS}$ and $\mathrm{AgS}_{2}$ coordinations, alternatively. However, for those which are in $\mathrm{AgS}_{2}$ coordination, one of the $\mathrm{Ag}-\mathrm{S}$ bonds is fairly long ( 2.8-3.0 Å), suggesting weaker interactions. Thus, cluster 7 exhibits a total of 36 strong Ag-S bonds. This is confirmed by DFT calculations, which allowed to view 7 as made of an 8 -je $\left[\mathrm{Ag}_{13}\right]^{5+}$ core $\left(1 \mathrm{~S}^{2}\right.$ $1 \mathrm{P}^{6}$ configuration) protected by an $\left[\mathrm{Ag}_{8}\left\{\mathrm{~S}_{2} \mathrm{P}\left(\mathrm{O}^{\mathrm{i}} \mathrm{Pr}\right)_{2}\right\}_{12}\right]^{4-}$ outer shell, made of $12 \mathrm{dtc}^{-}$ligands and 8 capping silver atoms (formally $\mathrm{Ag}^{+}$). The latter, being only weakly bonded to the $\left[\mathrm{Ag}_{13}\right]^{5+}$ core, but strongly to three sulphur atoms, can be described as trigonal-planar 16-electron centers.

3.1.2 $\left[\mathrm{Ag}_{20}\left\{\mathrm{~S}_{2} \mathbf{P}\left(\mathrm{O}^{\mathrm{i}} \mathrm{Pr}\right)_{2}\right\}_{12}\right]$ (8a): Lately, we reported the first structural evidence of silver superatoms having a chiral metallic core, namely $\left[\mathrm{Ag}_{20}\left\{\mathrm{~S}_{2} \mathrm{P}(\mathrm{OR})_{2}\right\}_{12}\right]\left(\mathrm{R}=\right.$ isopropyl, 8a and n-propyl, 8b). ${ }^{34}$ These species were produced through the simple removal (on the $C_{3}$ axis) of one of the 8 capping $\mathrm{Ag}^{+}$ cations from 7, without any other significant structural change, via either adding one equiv. borohydride or one-phase reduction. Thus, there is no difference between the molecular topologies of 7 and 8 (Figures 3 and 4), except that the latter is missing one of the two capping $\mathrm{Ag}^{+}$ions on the $C_{3}$ axis (Figure $4 \mathrm{a}-\mathrm{b}$ ). Thus, the $\mathrm{Ag}_{21}$ core of $D_{3 h}$ symmetry in the former becomes an $\mathrm{Ag}_{20}$ core of $C_{3}$ symmetry (a chiral group) in the latter. In the $\mathrm{Ag}_{20}$ core of $\mathbf{8}$, the 19 surface $\mathrm{Ag}$ atoms can be 
categorized into seven types of symmetry-related-atoms (shown as A-G in Figure 4b) in a ratio of 1:3:3:3:3:3:3. Three groups of every single Ag atom type create three clockwise helices along the $C_{3}$ axis (A-G in Figure 4c). Unfortunately, the isolated compound is racemic and no optical activity was observed in the CD spectra.

Cluster 8 can easily transform into the monocationic cluster $\mathbf{7}$ via the addition of one equiv. of silver (I) salt. They both are 8-je species and have distinct ${ }^{31} \mathrm{P}$ NMR shifts. ${ }^{33-34}$ The ease of silver uptake is parallel to the facile structural transformation between a hydride-centred tricapped tetrahedral silver cluster, $\left[\mathrm{Ag}_{7}(\mathrm{H})\left\{\mathrm{E}_{2} \mathrm{P}(\mathrm{OR})_{2}\right\}_{6}\right]$, and $\left[\mathrm{Ag}_{8}(\mathrm{H})\left\{\mathrm{E}_{2} \mathrm{P}(\mathrm{OR})_{2}\right\}_{6}\right]^{+}(\mathrm{E}=\mathrm{Se}, \mathrm{S})$, a hydride-centred tetracapped tetrahedron. ${ }^{47}$

3.1.3 [Au@ $\left.\mathbf{A g}_{19}\left\{\mathbf{S}_{2} \mathbf{P}\left(\mathbf{O}^{n} \mathbf{P r}\right)_{2}\right\}_{12}\right]$ (9): Heteroatom doping of chalcogenolated Ag clusters has been so far little explored..$^{6-7}$ In this context, we succeeded in preparing the silver alloy nanocluster 9 from the structurally characterized cluster $\mathbf{8 b}$ via reacting it with $\mathrm{Au}\left(\mathrm{PPh}_{3}\right) \mathrm{Cl}$ (a galvanic exchange route) ${ }^{35}$ Its structure is identical to that of its $\mathbf{8 b}$ parent (Figure 4d), ${ }^{34-35}$ with Au located at the cluster center. The Au central position can be easily understood from DFT calculations on the parent homonuclear 8 cluster in which the natural atomic charges of -0.44 (center), +0.23 (ico., avg.) and +0.63 (cap., avg.) indicate that the more electronegative Au atom will prefer the more electron-rich central site. Notably, the blue shifts in absorption and photoluminescence spectra upon doping show a strong influence of the central Au dopant atom. TD-DFT calculations found that in these species the band of lowest energy is associated with a charge transfer from the central atom to the other metal atoms.

Unfortunately, 9 has limited stability under harsh experimental conditions. However, adding formally one equiv. $\mathrm{Ag}^{+}$ion to this 20 metal atom cluster yielded the stable 21 metal atom cluster $\left[\mathrm{Au} @ \mathrm{Ag}_{20}\left\{\mathrm{~S}_{2} \mathrm{P}\left(\mathrm{O}^{\mathrm{n}} \mathrm{Pr}\right)_{2}\right\}_{12}\right]^{+}$. This transformation was monitored using ESI-MS and ${ }^{31} \mathrm{P}$ NMR, but the lack of crystal structure for $\left[\mathrm{Au} @ \mathrm{Ag}_{20}\left\{\mathrm{~S}_{2} \mathrm{P}\left(\mathrm{O}^{\mathrm{n}} \mathrm{Pr}\right)_{2}\right\}_{12}\right]^{+}$inhibited its mechanistic understanding. The shape flexibility of the cluster envelope and the particular stability of the 21-atom species are the possible key factors governing this transformation. In a recent contribution, ${ }^{41}$ similar size-structure transformation mechanistics were proved via single crystal structural study (see section 3.2.2.1). 


\subsection{8-je Closed Shell Diselenophosphate-Protected Ag-rich Superatoms}

The successful ligand exchange of dtps by incoming dseps raises the structure, stability and properties issues of such diselenolate species. The syntheses and structures of $\left[\mathrm{Ag}_{20}\left\{\mathrm{Se}_{2} \mathrm{P}\left(\mathrm{O}^{\mathrm{i}} \mathrm{Pr}\right)_{2}\right\}_{12}\right](\mathbf{1 0}),{ }^{40}$ $\left[\mathrm{Ag}_{21}\left\{\mathrm{Se}_{2} \mathrm{P}(\mathrm{OEt})_{2}\right\}_{12}\right]^{+}(\mathbf{1 1}),{ }^{40}$ and $\left[\mathrm{AuAg}_{20}\left\{\mathrm{Se}_{2} \mathrm{P}(\mathrm{OEt})_{2}\right\}_{12}\right]^{+}(\mathbf{1 2})^{40}$ are discussed below. Notably, prior to their report, there were no crystal structures available for selenolate-stabilized Ag nanoclusters.

\subsection{1 $\left[\mathrm{Ag}_{20}\left\{\mathrm{Se}_{2} \mathrm{P}\left(\mathrm{O}^{\mathrm{i}} \mathrm{Pr}\right)_{2}\right\}_{12}\right](10),\left[\mathrm{Ag}_{21}\left\{\mathrm{Se}_{2} \mathrm{P}(\mathrm{OEt})_{2}\right\}_{12}\right]^{+}(11)$, and $\left[\mathrm{AuAg}_{20}\left\{\mathrm{Se}_{2} \mathrm{P}(\mathrm{OEt})_{2}\right\}_{12}\right]^{+}(12)$ :}

Clusters 10 and 11 were fabricated via ligand exchange reactions from their thiolate counterparts, while 12 was generated via templated galvanic exchange of the latter with $\mathrm{Au}\left(\mathrm{PPh}_{3}\right) \mathrm{Cl} .{ }^{40}$ While the Xray structure of $\mathbf{1 0}$ is similar to that of its dtp counterpart $\mathbf{8 a}\left(C_{3}\right.$ symmetry, see above), cluster $\mathbf{1 1}$ (Figure 5) exhibits some structural differences with its thiolate relative 7 (Figure 3). Both are made of the same 8-je $\left[\mathrm{Ag}_{13}\right]^{5+}$ core but differ from the topology of their $\left[\mathrm{Ag}_{8}\left\{\mathrm{E}_{2} \mathrm{P}(\mathrm{OR})_{2}\right\}_{12}\right]^{4-}(\mathrm{E}=\mathrm{S}, \mathrm{Se})$ protecting shell. In particular, in $\mathbf{1 1}$, the 8 capping $\mathrm{Ag}^{+}$cations are forming a cube in which the $\left[\mathrm{Ag}_{13}\right]^{5+}$ core is engraved. ${ }^{40}$ The resulting ideal symmetry of the $\mathrm{Ag}_{21}$ unit is $O_{h}$ and that of the whole molecule is $T$ (as compared to $C_{3}$ in the case of 7). This $T$ structure was predicted to be stable before by DFT calculations. ${ }^{42}$ Cluster $\mathbf{1 1}$ has four 3-fold rotation axes passing through opposite cube vertices namely (Ag8, Ag7A), (Ag8A, Ag7), (Ag9, Ag10A), (Ag9A, Ag10) (Figure 5b). All 12 dsep ligands covering the $\mathrm{Ag}_{21}$ unit display the same type of bridging pattern of trimetallic triconnectivity $\left(\eta^{3}: \mu_{2}\right.$, $\mu_{1}$ ) with one $\mathrm{Ag}_{\text {ico }}$ and two $\mathrm{Ag}_{\text {cap }}$ atoms. The 8 capping $\mathrm{Ag}$ atoms are all in a near planar $\mathrm{AgSe}_{3}$ coordination mode.

The relatively high stability of $\mathbf{1 1}$, as compared to that of $\mathbf{1 0}$, motivated us to choose the former for Au doping. The X-ray structure of $\mathbf{1 2}$ reveals that it has the same space group as $\mathbf{1 1}$ and the same ideal $T$ symmetry, with the Au atom located at the centre of the icosahedron (Figure 5c-d). Similarly to what happens in the dithiolato series, the UV-Vis and photoluminescence spectra of $\mathbf{1 2}$ are found to be blue-shifted upon Au doping. As for their thiolato relative, DFT calculations indicate that a small energy difference exists between the $C_{3}$ and $T$ isomers. This suggests the possibility for several alternative arrangements of the outer shell (capping silver atoms and dichalcogenolate ligands). 
Calculations indicate also that the favoured occupation site for Au dopant is the center and the less favoured (by far) are the capping positions, whatever is the outer shell configuration.

3.2.2 $\left[\mathrm{Au}_{3} \mathrm{Ag}_{18}\left\{\mathrm{Se}_{2} \mathbf{P}\left(\mathrm{O}^{\mathrm{i}} \mathrm{Pr}\right)_{2}\right\}_{12}\right]$ (13): Unlike in $\mathrm{Au}_{\mathrm{n}}(\mathrm{SR})_{\mathrm{m}}$ chemistry, there is an extremely limited scope of increasing metal nuclearity in the case of thiolato Ag nanoclusters using the same ligand. Hence, it is challenging to increase the metal nuclearity keeping the homoleptic ligand nature. In the following, an unusual, heteroatom doping increases metal nuclearity is described. ${ }^{41}$

A galvanic exchange reaction was first conducted via reacting $\mathbf{1 0}$ with three equivalents of $\mathrm{Au}\left(\mathrm{PPh}_{3}\right) \mathrm{Cl}$ to generate $\left[\mathrm{Au}_{1+\mathrm{x}} \mathrm{Ag}_{20-\mathrm{x}}\left\{\mathrm{Se}_{2} \mathrm{P}\left(\mathrm{O}^{\mathrm{i}} \mathrm{Pr}\right)_{2}\right\}_{12}\right]^{+}$(x =0-2), which compositions were confirmed by ESI-MS. Two species, namely $\left[\mathrm{AuAg}_{20}\left\{\mathrm{Se}_{2} \mathrm{P}\left(\mathrm{O}^{\mathrm{i}} \mathrm{Pr}\right)_{2}\right\}_{12}\right]^{+}$and cluster 13, were successfully crystallized from the product mixture. ${ }^{41}$ The X-ray structure of $\left[\mathrm{AuAg}_{20}\left\{\mathrm{Se}_{2} \mathrm{P}\left(\mathrm{O}^{\mathrm{i}} \mathrm{Pr}\right)_{2}\right\}_{12}\right]^{+}$indicates that it is isostructural with that of $\mathbf{1 1}$ and $\mathbf{1 2}$ (of ideal $T$ symmetry). Cluster $\mathbf{1 3}$ crystallizes in the cubic I23 space group. It exhibits an $\mathrm{Au} @\left[\mathrm{Au}_{2} \mathrm{Ag}_{10}\right]$ centered icosahedron, where both second and third $\mathrm{Au}$ atoms prefer non-adjacent icosahedron vertices (Figure $6 \mathrm{a}-\mathrm{b}$ ). In the crystal, these two Au atoms are randomly distributed over three positions with $\sim 66.67 \%$ occupancy each related to a $C_{3}$ axis. As a result, the individual molecule is chiral with $C_{l}$ symmetry. However, due to isomer-averaging effect on chiroptical activity, the chiroptical responses could not be experimentally observed. The overall molecular topology of $\mathbf{1 3}$ is similar to that of $\left[\mathrm{AuAg}_{20}\left\{\mathrm{Se}_{2} \mathrm{P}\left(\mathrm{O}^{\mathrm{i}} \mathrm{Pr}\right)_{2}\right\}_{12}\right]^{+}$. Interestingly, UV-Vis absorption spectral studies demonstrate that the presence of an Au atom at the icosahedron center is a key factor for the electronic perturbation in Au doped $\left[\operatorname{Au}_{1+\mathrm{x}} @ \mathrm{Ag}_{20-\mathrm{x}}\left\{\operatorname{Se} \mathrm{S}_{2} \mathrm{P}\left(\mathrm{O}^{\mathrm{i}} \mathrm{Pr}\right)_{2}\right\}_{12}\right]^{+}, \mathrm{x}=0-2$. The role of the central Au atom for the electronic perturbations is fully supported by TD-DFT calculations indicating that the major electronic transitions involve a large central Au character.

DFT calculations found structure $T$ to be the most stable, in agreement with the observed structure. However, the alternative $C_{3}$ isomer is found lying only $1.3 \mathrm{kcal} / \mathrm{mol}$ above. A series of positional $\left[\mathrm{Au}_{3} \mathrm{Ag}_{18}\left(\mathrm{~S}_{2} \mathrm{PH}_{2}\right)_{12}\right]^{+}$isomers were also computed derived from the $T$ and $C_{3}$ structures. The most stable isomers were found to have Au atoms occupying the central and two non-adjacent surface 
icosahedral positions. The most stable structure in terms of free energy was found to correspond to the $\mathrm{X}$-ray structure of $\mathbf{1 3}$ as described above.

\section{Proposed Mechanism for Size-Structure Transformation:}

Taking into account the crystal structures along with DFT results, a unique mechanism is proposed for doping $\left[\mathrm{Ag}_{20}\left\{\mathrm{Se}_{2} \mathrm{P}\left(\mathrm{O}^{\mathrm{i}} \mathrm{Pr}\right)_{2}\right\}_{12}\right]$ with $\mathrm{Au}$ as shown below in Figure 7. This pathway follows the addition, galvanic replacement of dopants and reconstruction of the outer protecting shell. ${ }^{41}$ In the first step (a to b), addition of $\mathrm{Au}(\mathrm{I})$ provides the 8th capping atom to form $\left[\left(\mathrm{Ag} @ \mathrm{Ag}_{12}\right)\left(\mathrm{AuAg}_{7}\right)\left\{\mathrm{Se}_{2} \mathrm{P}\left(\mathrm{O}^{\mathrm{i}} \mathrm{Pr}\right)_{2}\right\}_{12}\right]^{+}$. As $\mathrm{Au}$ has a strong preference for occupying the icosahedron centre, the capping $\mathrm{Au}(\mathrm{I})$ atom goes to the center, being galvanically reduced by $\operatorname{Ag}(0)$ (b to c). The latter is expelled as $\operatorname{Ag}(\mathrm{I})$ and migrates to capping positions (c to d). As a result, $\left[\left(\mathrm{Au} @ \mathrm{Ag}_{12}\right)\left(\mathrm{Ag}_{8}\right)\left\{\mathrm{Se}_{2} \mathrm{P}\left(\mathrm{O}{ }^{\mathrm{i}} \mathrm{Pr}\right)_{2}\right\}_{12}\right]^{+}$in $T$ or $C_{3}$ symmetry is generated (e and f). Keeping in mind that both $\left[\mathrm{Ag}_{20}\left\{\mathrm{Se}_{2} \mathrm{P}\left(\mathrm{O}^{\mathrm{i}} \mathrm{Pr}\right)_{2}\right\}_{12}\right]$ template and product 13 display the closed-shell superatomic 8-je configuration, we propose that the more stable geometric structure of $\mathbf{1 3}$ plays a pivotal role for above transformation, shown in Figure 7.

\subsection{Rich Isomerism Potentials Uncovered from Capping Silver Positions Around Centerd- Icosahedral $\mathrm{Ag}_{13}\left(\right.$ or $\mathrm{AuAg}_{12}$ ) Core}

Topologically, several positional isomers are possible for an octacapped centered icosahedron $\left(\mu_{3^{-}}\right.$ $\mathrm{Ag})_{8} \mathrm{Ag}_{13}$. However, the number of possibilities is substantially reduced when considering the orientation of the twelve dichalcogenolate ligands occupying equal space around a sphere and displaying a fixed number of strong $\mathrm{Ag}-\mathrm{E}(\mathrm{E}=\mathrm{S}, \mathrm{Se})$ bonds, i.e. 36 (12 with the icosahedral metals and $8 \times 3$ with the capping atoms). To date, two stable conformations have been structurally confirmed: one of $C_{3}$ symmetry exhibited by 7 and one of $T$ symmetry exemplified by $\mathbf{1 1}$. As mentioned above, the $C_{3}$ structure of $\mathbf{8 a}$ can be formally generated from the $\mathrm{Ag}_{21} C_{3}$ structure by removing one of the capping $\mathrm{Ag}^{+}$located on the 3-fold axis. Removing one of the capping atoms which are not located on the 3-fold axis generates another structure, which is of $C_{l}$ symmetry. Another $\mathrm{Ag}_{20}$ structure, also of $C_{l}$ symmetry, has been experimentally characterized for $\mathbf{8 b} .{ }^{34}$ It can be derived from that of $\mathbf{8}\left(C_{3}\right)$ by simply moving one capping atom lying on the 3 -fold axis to another position. Finally, removing one 
of the capping atoms from the $\mathrm{Ag}_{21} T$ structure generates another $\mathrm{Ag}_{20}$ isomer of $C_{3}$ symmetry. DFT model calculations (Figure 8) indicate that in both series the computed isomers are almost isoenergetic. Very similar results were computed for the diselenolate analogs, ${ }^{40-41}$ as well as the $\mathrm{Au} @ \mathrm{Ag}_{\mathrm{x}}$ $(x=20,19)$ series. Thus, several potential isomers are feasible, with different properties which may be explored. In particular, the optical properties are influenced by the positions of the capping atoms, due to the participation of these atoms in the excited state electron density. Such a unique type of isomerism caused by the spacial arrangement of protecting shell around the icosahedral core has been rarely reported for $\left[\mathrm{M}_{25}(\mathrm{SR})_{18}\right]^{-}(\mathrm{M}=\mathrm{Au}, \mathrm{Ag}){ }^{28}$ This could be due to the chelated effect imposed by the dichalcogenolate ligands, which stabilized the eight-electron superatomic core.

\section{CONCLUDING REMARKS}

Because of the bidentate nature of the formally monoanionic dichalcogenolate ligands, their use in the synthesis of group 11 nanoclusters leads to the isolation of stable superatoms of composition and structure different from that obtained with monodentate thiolate ligands. Taking advantage of their subnanometer size and rigid ligand shell, single-crystals of appropriate quality can be grown for detailed structural analysis.

For example, the 2-je superatom $\left[\mathrm{Cu}_{13}\left(\mathrm{~S}_{2} \mathrm{CN}^{\mathrm{n}} \mathrm{Bu}_{2}\right)_{6}(\mathrm{C} \equiv \mathrm{CPh})_{4}\right]^{+}$exhibits a unique $\mathrm{Cu}_{13}$ centred cuboctahedral core, a miniature of the bulk $\mathrm{Cu}$ in fcc. The preference for a cuboctahedral over the alternative icosahedral arrangement is likely to be induced by the propensity of the bidentate dtc ligands to cap square faces. Here, the central $\mathrm{Cu}$ atom, being in a low oxidation state, can be galvanically replaced by $\mathrm{Ag} / \mathrm{Au}$, leading to $\mathrm{Cu}$-rich bimetallic alloys. The presence of $\mathrm{Au}$ or $\mathrm{Ag}$ atoms at centre of the $\mathrm{Cu}_{12}$ cuboctahedron has profound effects on the physiochemical properties. For example, $\quad\left[\mathrm{Au} @ \mathrm{Cu}_{12}\left(\mathrm{~S}_{2} \mathrm{CN}^{\mathrm{n}} \mathrm{Bu}_{2}\right)_{6}(\mathrm{C} \equiv \mathrm{CPh})_{4}\right]^{+}$and $\left[\mathrm{Au} @ \mathrm{Cu}_{12}\left\{\mathrm{~S}_{2} \mathrm{P}\left(\mathrm{O}{ }^{\mathrm{i}} \mathrm{Pr}\right)_{2}\right\}_{6}(\mathrm{C} \equiv \mathrm{CPh})_{4}\right]^{+}$display a dramatic enhancement in emission intensity and quantum yield compared to the parent $\mathrm{Cu}_{13}$ cluster. Such type of highly luminescent nanoscale materials offers promising applications in sensing and biolabeling. ${ }^{48}$ 
In the case of silver, several $\mathrm{Ag}_{21}$ 8-je species have been isolated, as exemplified by $\left[\mathrm{Ag}_{21}\left\{\mathrm{~S}_{2} \mathrm{P}\left(\mathrm{O}^{\mathrm{i}} \mathrm{Pr}\right)\right.\right.$ $\left.\left.{ }_{2}\right\}_{12}\right]^{+}$, which exhibits a unique non-hollow (centred) $\mathrm{Ag}_{13}$ icosahedron, capped by $8 \mathrm{Ag}$ atoms and 12 dtp ligands. Obviously, this metal-ligand interface is different from that of the ubiquitous $\mathrm{Au}_{2}(\mathrm{SR})_{3^{-}}$ type staple motifs present in the thiolate-passivated $\mathrm{Au}_{25}$ species. Furthermore, under some conditions, $\left[\mathrm{Ag}_{21}\left\{\mathrm{~S}_{2} \mathrm{P}\left(\mathrm{O}^{\mathrm{i}} \mathrm{Pr}\right)_{2}\right\}_{12}\right]^{+}$can lose $\mathrm{Ag}^{+}$, giving rise to $\left[\mathrm{Ag}_{20}\left\{\mathrm{~S}_{2} \mathrm{P}\left(\mathrm{O}^{\mathrm{i}} \mathrm{Pr}\right)_{2}\right\}_{12}\right]$, which is the first structural paradigm with a chiral inorganic core reported by our group. Interestingly, diselenolate systems such as $\left[\mathrm{AuAg}_{20}\left\{\mathrm{Se}_{2} \mathrm{P}(\mathrm{OEt})_{2}\right\}_{12}\right]^{+}$and $\left[\mathrm{Ag}_{21}\left\{\mathrm{Se}_{2} \mathrm{P}(\mathrm{OEt})_{2}\right\}_{12}\right]^{+}$were found to have idealized $T$ symmetry different from the $C_{3}$ symmetry of $\left[\mathrm{Ag}_{20}\left\{\mathrm{Se}_{2} \mathrm{P}\left(\mathrm{O}^{\mathrm{i}} \mathrm{Pr}\right)_{2}\right\}_{12}\right]$ and the thiolate counterparts. It is also possible to increase the metal nuclearity at a single atomic level via heteroatom doping of Au into $\left[\mathrm{Ag}_{20}\left\{\mathrm{Se}{ }_{2} \mathrm{P}\left(\mathrm{O}^{\mathrm{i}} \mathrm{Pr}\right)_{2}\right\}_{12}\right]$ to produce $\left[\mathrm{Au}_{3} \mathrm{Ag}_{18}\left\{\mathrm{Se} e_{2} \mathrm{P}\left(\mathrm{O}^{\mathrm{i}} \mathrm{Pr}\right)_{2}\right\}_{12}\right]^{+}$.

The major challenge today is to stabilize mono or doped chalcogenolate-protected copper and silver superatoms with higher nuclearities and electron counts. To reach this goal, the use of auxiliary ligands such as alkynyls ${ }^{11-15}$ and an alternative one-phase reduction appear to be promising. We expect that this account will enrich the understanding of alloy clusters and thus will incite the interest among scientists.

\section{AUTHOR INFORMATION}

\section{Corresponding Author}

*E-mail: chenwei@mail.ndhu.edu.tw; saillard@univ-rennes1.fr

\section{Notes}

The authors declare no competing financial interests.

\section{ORCID}

Chen-Wei Liu: 0000-0003-0801-6499 
Jean-Yves Saillard: 0000-0003-4469-7922

\section{Biographical Information}

Sachil Sharma is a postdoctoral researcher in Prof. Liu's group in National Dong Hwa University (NDHU). His research interests include the synthesis and functionalization of noble metal nanoclusters.

Kiran Kumarvarma Chakrahari is a postdoctoral researcher in Prof. Liu's group in NDHU. His research interests are the synthesis of copper hydrides and superatomic alloys.

Jean-Yves Saillard is a professor emeritus at the University of Rennes 1. He is interested in the electronic structure of clusters.

Chen-Wei Liu is a distinguished professor at the chemistry department in NDHU. His research is mainly devoted to the synthesis of dichalcogenolate-protected group 11 metal clusters.

\section{ACKNOWLEDGMENTS}

This work was supported by the Ministry of Science and Technology in Taiwan (MOST 1062113-M-259-010). Dr. Samia Kahlal and our collaborators, whose names are given in the references, are warmly acknowledged for their contributions to the work reported here.

\section{REFERENCES}

1. Jin, R.; Zeng, C.; Zhou, M.; Chen, Y. Atomically Precise Colloidal Metal Nanoclusters and Nanoparticles: Fundamentals and Opportunities. Chem. Rev. 2016, 116, 1034610413.

2. Jin, R. Atomically precise metal nanoclusters: stable sizes and optical properties. Nanoscale 2015, 7, 1549-1565.

3. Yu, H.; Rao, B.; Jiang, W.; Yang, S.; Zhu, M. The photoluminescent metal nanoclusters with atomic precision. Coord. Chem. Rev. 2017, DOI: 10.1016/j.ccr.2017.12.005. 
4. Parker, J. F.; Fields-Zinna, C. A.; Murray, R. W. The Story of a Monodisperse Gold Nanoparticle: $\mathrm{Au}_{25} \mathrm{~L}_{18}$. Acc. Chem. Res. 2010, 43, 1289-1296.

5. Knoppe, S.; Bürgi, T. Chirality in Thiolated-Protected Gold Clusters. Acc. Chem. Res. 2014, 47, 1318-1326.

6. Jin, R.; Zhao, S.; Xing, Y.; Jin, R. All-thiolate-protected silver and silver-rich alloy nanoclusters with atomic precision: stable sizes, structural characterization and optical properties. CrystEngComm 2016, 18, 3996-4005.

7. Chakraborty, I.; Pradeep, T. Atomically Precise Clusters of Noble Metals: Emerging Link between Atoms and Nanoparticles. Chem. Rev. 2017, 117, 8208-8271.

8. Liu, X.; Astruc, D. Atomically precise copper nanoclusters and their applications. Coord. Chem. Rev. 2018, 359, 112-126.

9. Leuchtner, R. E.; Harms, A. C.; Castleman Jr., A. W. Thermal metal cluster anion reactions: Behavior of aluminum clusters with oxygen. J. Chem. Phys. 1989, 91, 27532754.

10. Walter, M.; Akola, J.; Lopez-Acevedo, O.; Jadzinsky, P. D.; Calero, G.; Ackerson, C. J.; Whetten, R. L.; Gronbeck, H.; Hakkinen, H. A unified view of ligand protected gold clusters as superatom complexes. Proc. Natl. Acad. Sci. USA 2008, 10, 9157-9162.

11. Nguyen, T.-A. D.; Jones, Z. R.; Goldsmith, B. R.; Buratto, W. R.; Wu, G.; Scott, S. L.; Hayton, T. W. $\mathrm{A} \mathrm{Cu}_{25}$ Nanocluster with Partial $\mathrm{Cu}(0)$ Character. J. Am. Chem. Soc. 2015, $137,13319-13324$.

12. Nguyen, T.-A. D.; Jones, Z. R.; Leto, D. F.; Wu, G.; Scott, S. L.; Hayton, T. W. Ligand Exchange Mediates the Growth of an Atomically Precise $\mathrm{Cu}_{29}$ Nanocluster from a Smaller Cluster. Chem. Mater. 2016, 28, 8385-8390.

13. Cook, A. W.; Jones, Z. R.; Wu, G.; Scott, S. L.; Hayton, T. W. An Organometallic $\mathrm{Cu}_{20}$ Nanocluster: Synthesis, Characterization, Immobilization on Silica, and "Click" Chemistry. J. Am. Chem. Soc., 2018, 140, 394-400. 
14. Chakrahari, K. K.; Liao, J.-H.; Kahlal, S.; Liu, Y.-C.; Chiang, M.-H.; Saillard, J.-Y.; Liu, C. W. $\left.\left[\mathrm{Cu}_{13}\left\{\mathrm{~S}_{2} \mathrm{CN}^{n} \mathrm{Bu}_{2}\right\}_{6} \text { (acetylide }\right)_{4}\right]^{+}$: A Two-Electron Superatom. Angew. Chem. Int. Ed. 2016, 55, 14704-14708.

15. Silalahi, R. P. B.; Chakrahari, K. K.; Liao, J.-H.; Kahlal, S.; Liu, Y.-C.; Chiang, M.-H.; Saillard, J.-Y.; Liu, C. W. Synthesis of Two-Electron Bimetallic Cu-Ag and $\mathrm{Cu}-\mathrm{Au}$ Clusters by using $\left[\mathrm{Cu}_{13}\left(\mathrm{~S}_{2} \mathrm{CN}^{n} \mathrm{Bu}_{2}\right)_{6}(\mathrm{C} \equiv \mathrm{CPh})_{4}\right]^{+}$as a Template. Chem. Asian J. 2018, 13, 500-504.

16. Kang, X.; Wang, S.; Song, Y.; Jin, S.; Sun, G.; Yu, H.; Zhu, M. Bimetallic $\mathrm{Au}_{2} \mathrm{Cu}_{6}$ Nanoclusters: Strong Luminescence Induced by the Aggregation of Copper(I) Complexes with Gold(0) Species. Angew. Chem. Int. Ed. 2016, 55, $3611-3614$.

17. Yang, H.; Wang, Y.; Yan, J.; Chen, X.; Zhang, X.; Hakkinen, H.; Zheng, N. Structural Evolution of Atomically Precise Thiolated Bimetallic $\left[\mathrm{Au}_{12+n} \mathrm{Cu}_{32}(\mathrm{SR})_{30+n}\right]^{4-}(n=0,2,4$, 6) Nanoclusters. J. Am. Chem. Soc. 2014, 136, $7197-7200$.

18. Yan, J.; Su, H.; Yang, H.; Hu, C.; Malola, S.; Lin, S.; Teo, B. K.; Hakinen, H.; Zheng. N. Asymmetric Synthesis of Chiral Bimetallic $\left[\mathrm{Ag}_{28} \mathrm{Cu}_{12}(\mathrm{SR})_{24}\right]^{4-}$ Nanoclusters via Ion Pairing. J. Am. Chem. Soc. 2016, 138, $12751-12754$.

19. Weßing, J.; Ganesamoorthy, C.; Kahlal, S.; Marchal, R.; Gemel, C.; Cador, O.; Silva, A. C. H. D.; Silva, J. L. F. D. Saillard J.-Y.; Fischer, R. A. The Mackay-type Cluster $\left.\left[\mathrm{Cu}_{43} \mathrm{Al}_{12}\right]\left(\mathrm{Cp}^{*}\right)_{12}\right]$ : Open-Shell 67-Electron Superatom with Emerging Metal-Like Electronic Structure. Angew. Chem. DOI: 10.1002/anie.201806039.

20. Gam, F.; Paez-Hernandez, D.; Arratia-Perez, R.; Liu, C. W.; Kahlal, S.; Saillard, J.-Y.; Munoz-Castro, A. Coinage Metal Superatomic Cores: Insights into Their Intrinsic Stability and Optical Properties from Relativistic DFT Calculations. Chem. Eur. J., 2017, 23, 11330-11337.

21. Dhayal, R. S.; Zyl, W. E. V.; Liu, C. W. Polyhydrido Copper Clusters: Synthetic advances, structural diversity, and nanocluster-to-nanoparticle conversion. Acc. Chem. Res. 2016, 49, 86-95. 
22. Edwards, A. J.; Dhayal, R. S.; Liao, P.-K.; Liao, J.-H.; Chiang, M.-H.; Piltz, R. O.; Kahlal, S.; Saillard, J.-Y.; Liu, C. W. Chinese Puzzle Molecule: A 15 Hydride, 28 Copper Atom Nanoball. Angew. Chem., Int. Ed. 2014, 53, 7214-7218.

23. Chakrahari, K. K.; Silalahi, R. P. B.; Liao, J.-H.; Kahlal, S.; Liu, Y.-C.; Lee, J.-F.; Chiang, M.-H.; Saillard, J.-Y.; Liu, C. W. Synthesis and Structural Characterization of Inverse-Coordination Clusters from a Two-Electron Superatomic Copper Nanocluster. Chem. Sci. 2018, 9, 6785-6795.

24. Dhayal, R. S.; Liao, J.-H.; Kahlal, S.; Wang, X.; Liu, Y.-C.; Chiang, M.-H.; Van Zyl, W. E.; Saillard, J.-Y.; Liu, C. W. $\left[\mathrm{Cu}_{32}(\mathrm{H})_{20}\left\{\mathrm{~S}_{2} \mathrm{P}\left(\mathrm{O}^{i} \mathrm{Pr}\right)_{2}\right\}_{12}\right]$ : The Largest Number of Hydrides Recorded in a Molecular Nanocluster by Neutron Diffraction. Chem. Eur. J. 2015, 21, 8369-8374.

25. Yang, H.; Lei, J.; Wu, B.; Wang, Y.; Zhou, M.; Xia, A.; Zheng, L.; Zheng, N. Crystal structure of a luminescent thiolated $\mathrm{Ag}$ nanocluster with an octahedral $\mathrm{Ag}_{6}{ }^{4+}$ core. Chem. Commun. 2013, 49, 300-302.

26. Yang, H.; Wang, Y.; Zheng, N. Stabilizing subnanometer $\operatorname{Ag}(0)$ nanoclusters by thiolate and diphosphine ligands and their crystal structures. Nanoscale 2013, 5, 2674-2677.

27. Joshi, C. P.; Bootharaju, M. S.; Alhilaly. M. J.; Bakr, O. M. $\left[\mathrm{Ag}_{25}(\mathrm{SR})_{18}\right]^{-}$The "Golden" Silver Nanoparticle. J. Am. Chem. Soc. 2015, 137, 11578-11581.

28. Bootharaju, M. S.; Joshi, C. P.; Parida, M. S.; Mohammed, O. F.; Bakr, O. M. Templated Atom-Precise Galvanic Synthesis and Structure Elucidation of a $\left[\mathrm{Ag}_{24} \mathrm{Au}(\mathrm{SR})_{18}\right]^{-}$ Nanocluster. Angew. Chem. Int. Ed. 2016, 55, 922-926.

29. Desireddy, A.; Conn, B. C.; Guo, J.; Yoon, B.; Barnett, R. N.; Monahan, B. N.; Kirschbaum, K.; Griffith, W. P.; Whetten, R. L.; Landman, U.; Bigioni, T. P. Ultrastable Silver nanoparticles. Nature, 2013, 501, 399-402.

30. Yang, H.; Wang, Y.; Huang, H.; Gell, L.; Lehtovaara, L.; Malola, S.; Hakkinen, H.; Zheng, N. Nature Commun. All-thiol-stabilized $\mathrm{Ag}_{44}$ and $\mathrm{Au}_{12} \mathrm{Ag}_{32}$ nanoparticles with single-crystal structures. 2013, 4, 2422. 
31. Yan, J.; Su, H. Yang, H.; Malola, S.; Lin, S.; Häkkinen, H.; Zheng, N. Total Structure and Electronic Structure Analysis of Doped Thiolated Silver $\left[\mathrm{MAg}_{24}(\mathrm{SR})_{18}\right]^{2-}(\mathrm{M}=\mathrm{Pd}, \mathrm{Pt})$ Clusters. J. Am. Chem. Soc. 2015, 137, 11880-11883.

32. Jin, S.; Xu, F.; Du, W.; Kang, X.; Chen, S.; Zhang, J.; Li, X.; Hu, D.; Wang, S.; Zhu, M. Isomerism in $\mathrm{Au}-\mathrm{Ag}$ Alloy Nanoclusters: Structure Determination and Enantioseparation of $\left[\mathrm{Au}_{9} \mathrm{Ag}_{12}(\mathrm{SR})_{4}(\mathrm{dppm})_{6} \mathrm{X}_{6}\right]^{3+}$. Inorg. Chem. 2018, 57, 5114-5119.

33. Dhayal, R. S.; Liao, J.-H.; Liu, Y.-C.; Chiang, M.-H.; Kahlal, S.; Saillard, J.-Y.; Liu. C. W. $\left[\mathrm{Ag}_{21}\left\{\mathrm{~S}_{2} \mathrm{P}\left(\mathrm{O}^{\mathrm{i}} \mathrm{Pr}\right)_{2}\right\}_{12}\right]^{+}:$An eight-Electron Superatom. Angew. Chem. Int. Ed. 2015, 54, $3702-3706$.

34. Dhayal, R. S.; Lin, Y.-R.; Liao, J.-H.; Chen, Y.-J.; Liu, Y.-C.; Chiang, M.-H.; Kahlal, S.; Saillard, J.-Y.; Liu. C. W. $\left[\operatorname{Ag}_{20}\left\{\mathrm{~S}_{2} \mathrm{P}(\mathrm{OR})_{2}\right\}_{12}\right]$ : A superatom complex with a chiral Metallic Core and High Potential for Isomerism. Chem. Eur. J. 2016, 22, 9943-9947.

35. Lin, Y.-R.; Kishore, P. V. V. N.; Liao, J.-H.; Kahlal, S.; Liu, Y.-C.; Chiang, M.-H.; Saillard, J.-Y.; Liu, C. W. Synthesis, structural characterization and transformation of an eight-electron superatomic alloy, [Au@ $\left.\operatorname{Ag}_{19}\left\{\mathrm{~S}_{2} \mathrm{P}(\mathrm{OPr})_{2}\right\}_{12}\right]$. Nanoscale 2018, 10, 68556860.

36. AbdulHalim, L. G.; Bootharaju, M. S.; Tang, Q.; Gobbo, S. D.; AbdulHalim, R. G.; Eddaoudi, M.; Jiang, D.; Bakr, O. M. $\operatorname{Ag}_{29}(\mathrm{BDT})_{12}(\mathrm{TPP})_{4}$ : A Tetravalent Nanocluster. $J$. Am. Chem. Soc. 2015, 137, 11970-11975.

37. Kang, X.; Xiong, L.; Wang, S.; Yu, H.; Jin, S.; Song, Y.; Chen, T.; Zheng, L.; Pan, C.; Pei, Y.; Zhu. M. Shape-controlled synthesis of Trimetallic Nanoclusters: Structure Elucidation and Properties Investigation. Chem. Eur. J. 2016, 22, 17145-17150.

38. Bootharaju, M. S.; Kozlov, S. M.; Cao, Z.; Shkurenko, A.; El-Zohry, A. M.; Mohammed, O. F.; Eddaoudi, M.; Bakr, O. M.; Cavallo, L.; Basset, J.-M. Tailoring the Crystal Structure of Nanoclusters Unveiled High Photoluminescence via Ion Pairing. Chem. Mater. 2018, 30, 2719-2725. 
39. Kang, X.; Zhou, M.; Wang, S.; Jin, S.; Sun, G.; Zhu, M.; Jin, R. The tetrahedral structure and luminescence properties of bi-metallic $\mathrm{Pt}_{1} \mathrm{Ag}_{28}(\mathrm{SR})_{18}\left(\mathrm{PPh}_{3}\right)_{4}$ nanocluster. Chem. Sci. 2017, $8,2581-2587$.

40. Chang, W.-T.; Lee, P.-Y.; Liao, J.-H.; Chakrahari, K. K.; Kahlal, S.; Liu, Y.-C.; Chiang, M.-H.; Saillard. J.-Y.; Liu, C. W. Eight-Electron Silver and Mixed Gold/Silver Nanoclusters stabilized by Selenium Donor Ligands. Angew. Chem. Int. Ed. 2017, 56, 10178-10182.

41. Chang, W.-T.; Sharma. S.; Liao, J.-H.; Kahlal, S.; Liu, Y.-C.; Chiang, M.-H.; Saillard. J.Y.; Liu, C. W. Heteroatom-Doping Increases Cluster Nuclearity: From An $\left[\mathrm{Ag}_{20}\right]$ to An [ $\left.\mathrm{Au}_{3} \mathrm{Ag}_{18}\right]$ core. Chem. Eur. J. 2018, DOI: 10.1002/chem.201802679.

42. Chen, T.; Yang, S.; Chai, J.; Song, Y.; Fan, J.; Rao, B.; Sheng, H.; Yu, H.; Zhu, M. Crystallization-induced emission enhancement: A novel fluorescent $\mathrm{Au}-\mathrm{Ag}$ bimetallic nano cluster with precise atomic structure. Sci. Adv. 2017, 3, e1700956.

43. He, L.; Yuan, J.; Xia, N.; Liao, L.; Liu. X.; Gan, Z.; Wang, C.; Yang, J.; Wu, Z. Kernel Tuning and Nonuniform Influence on optical and Electrochemical gaps of Bimetal Nanoclusters. J. Am. Chem. Soc. 2018, 140, 3487-3490.

44. Li, Q.; Wang, S.; Kirschbaum, K.; Lambright, K. J.; Das, A.; Jin, R. Heavily doped $\mathrm{Au}_{25-\mathrm{x}} \mathrm{Ag}_{\mathrm{x}}\left(\mathrm{SC}_{6} \mathrm{H}_{11}\right)_{18}{ }^{-}$nanoclusters: silver goes from the core to the surface, Chem. Commun.2016, 52, 5194-5197.

45. Jin, R.; Zhao, S.; Liu, C.; Zhou, M.; Panapitiya, G.; Xing, Y.; Rosi, N. L.; Lewis, J. P.; Jin, R. Controlling Ag-doping in $\left[\mathrm{Ag}_{\mathrm{x}} \mathrm{Au}_{25-\mathrm{x}}\left(\mathrm{SC}_{6} \mathrm{H}_{11}\right)_{18}\right]^{-}$nanoclusters: cryogenic optical, electronic and electrocatalytic properties. Nanoscale 2017, 9, 19183-19190.

46. Zhu, M.; Aikens, C. M.; Hollander, F. J.; Schatz, G. C.; Jin, R. Correlating the Crytal Structure of A Thiol-Protected $\mathrm{Au}_{25}$ Cluster and Optical Properties. J. Am. Chem. Soc. 2008, $130,5883-5885$. 
47. Liu, C. W.; Lin, Y.-R.; Fang, C.-S.; Latouche, C.; Kahlal, S.; Saillard, J.-Y. $\left[\mathrm{Ag}_{7}(\mathrm{H})\left\{\mathrm{E}_{2} \mathrm{P}(\mathrm{OR})_{2}\right\}_{6}\right](\mathrm{E}=\mathrm{Se}, \mathrm{S})$ : Precursors for the Fabrication of Silver Nanoparticles. Inorg. Chem. 2013, 52, 2070-2077.

48. Wang, S.; Meng, X.; Das, A.; Li, T.; Song, Y.; Cao, T.; Zhu, X.; Zhu, M.; Jin, R. A 200fold Quantum Yield Boost in the Photoluminescence of Silver-Doped $\operatorname{Ag}_{x} A_{25-x}$ Nanoclusters: The 13th Silver Atom Matters. Angew. Chem. Int. Ed. 2014, 53, 23762380. 

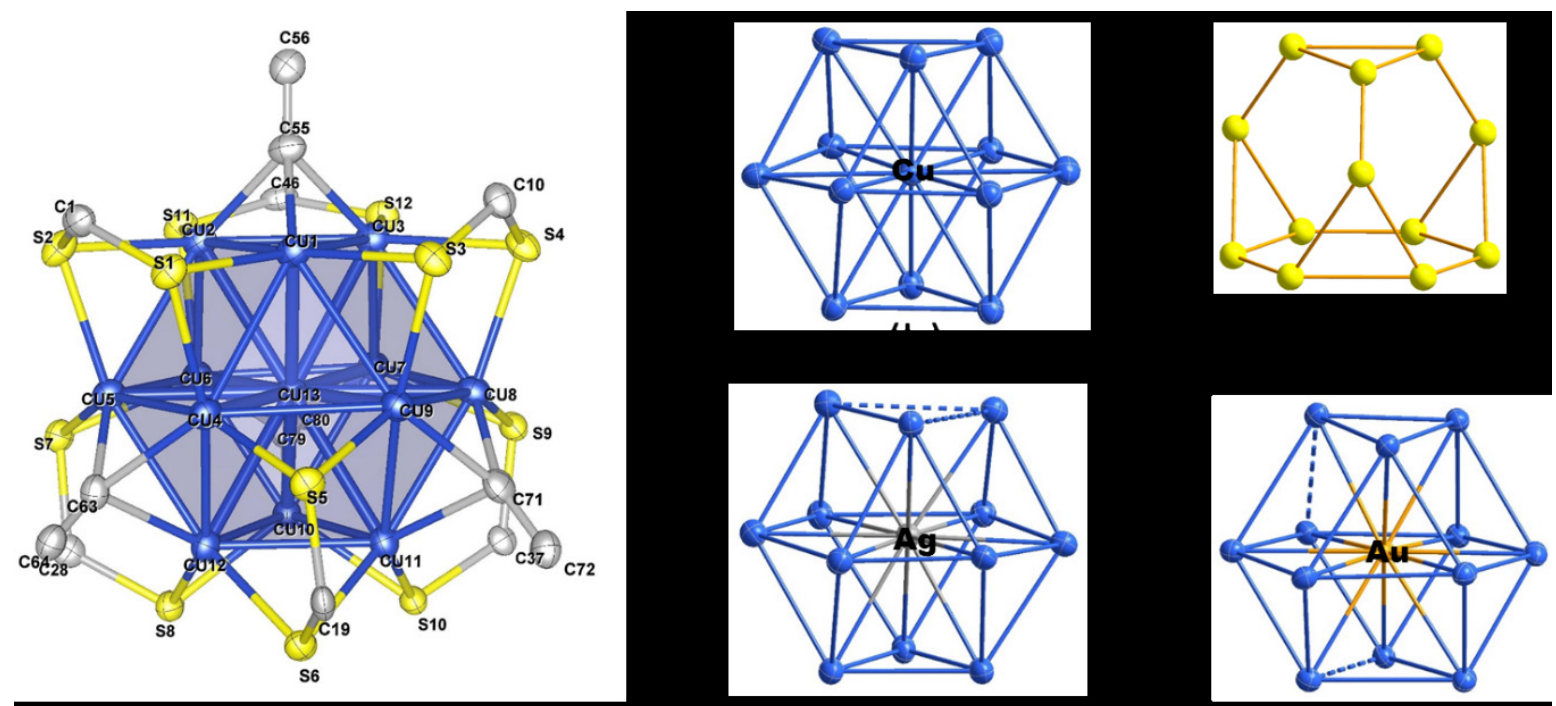

Figure 1. (a) X-ray structure of $\left[\mathrm{Cu}_{13}\left\{\mathrm{~S}_{2} \mathrm{CN}^{\mathrm{n}} \mathrm{Bu}_{2}\right\}_{6}(\mathrm{CCPh})_{4}\right]^{+}$(4a) with $\mathrm{N}^{n} \mathrm{Bu}_{2}$ and phenyl moieties omitted for clarity; (b) the centred cuboctahedron framework of 13 copper atoms; (c) the 12 sulfur atoms in a truncated tetrahedral geometry which surround the copper core. The centred cuboctahedron framework of $5 \mathrm{Ag} @ \mathrm{Cu}_{12}(\mathrm{~d})$, and $6 \mathrm{Au} @ \mathrm{Cu}_{12}(\mathrm{e})$.

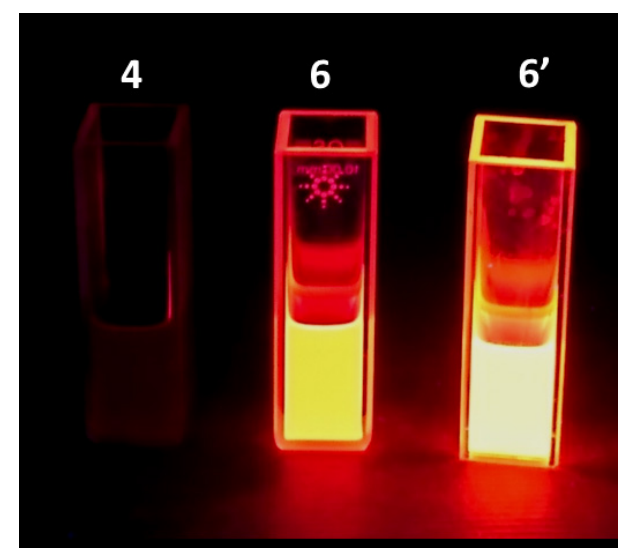

Figure 2. Photographs of 4, 6, 6' under UV-excitation at ambient temperature. 

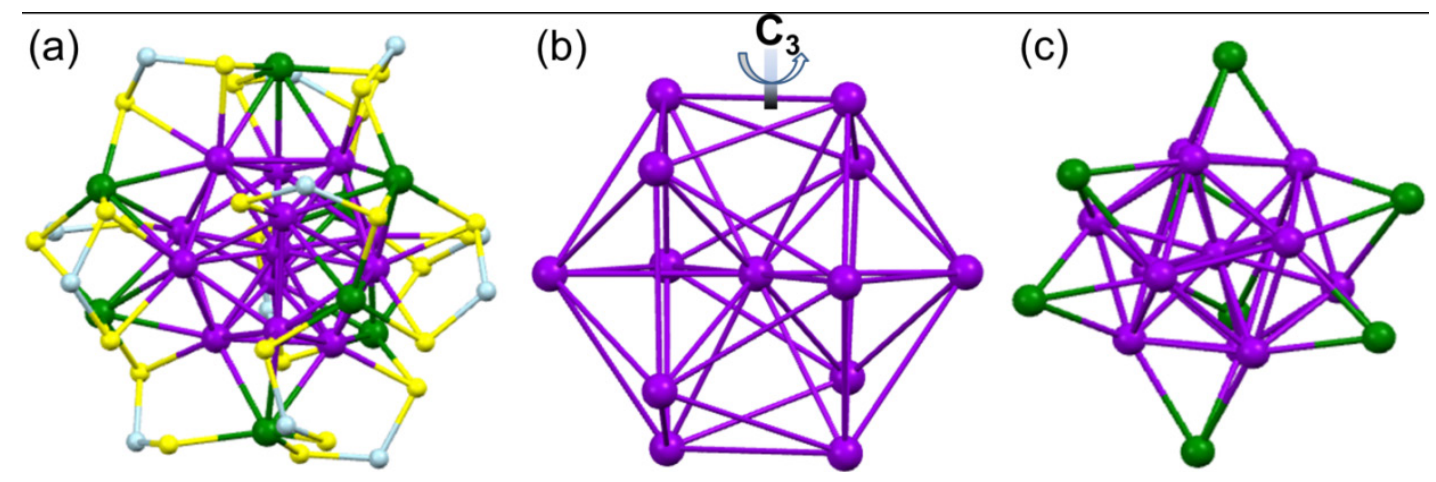

Figure 3. (a) Total structure of $\left[\mathrm{Ag}_{21}\left\{\mathrm{~S}_{2} \mathrm{P}\left(\mathrm{O}^{\mathrm{i}} \mathrm{Pr}\right)\right\}_{12}\right]^{+}$with isopropoxy groups omitted for clarity; (b) the 8-je $\left[\mathrm{Ag}_{13}\right]^{5+}$ core; (c) the $\mathrm{Ag}_{21}$ core. Color code: $\mathrm{Ag}$ purple and green, $\mathrm{S}$ yellow, $\mathrm{P}$ light blue. Reproduced with permission from ref. 33. Copyright 2015 Wiley-VCH.
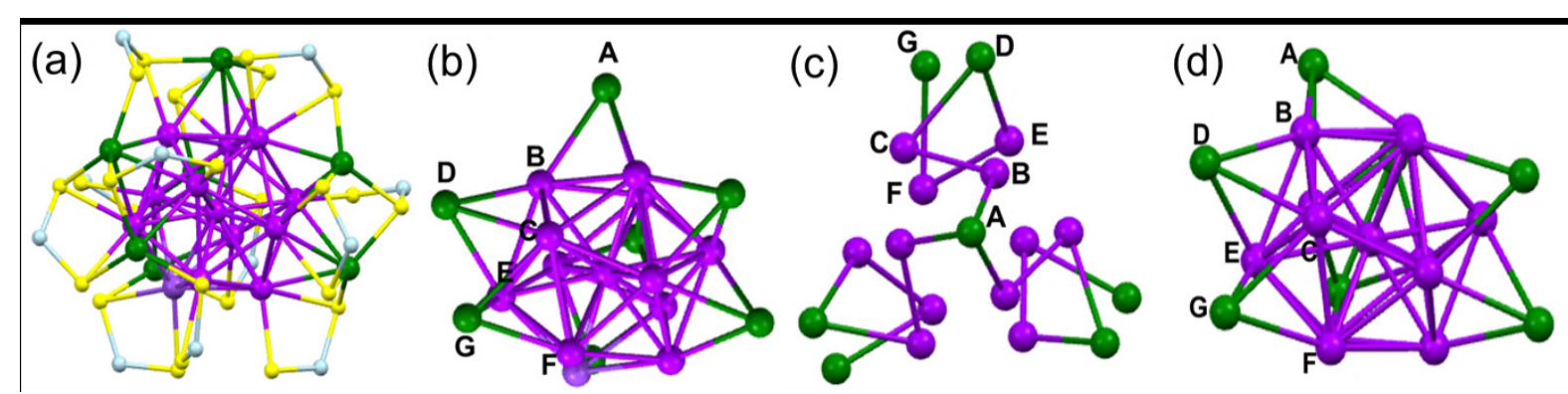

Figure 4 (a) Total structure of $\left[\mathrm{Ag}_{20}\left\{\mathrm{~S}_{2} \mathrm{P}\left(\mathrm{O}^{\mathrm{i}} \mathrm{Pr}\right)_{2}\right\}_{12}\right]$ (8a) with isopropoxy groups omitted for clarity; (b) out of seven capping Ag atoms (green), six form a butterfly group around the $C_{3}$ axis and labelling of different surface atoms types (A-G); (c) top view of three clockwise silver strands constituting the $\mathrm{Ag}_{20}$ core; (d) the $\mathrm{Ag}_{20}$ core of $\left.\mathrm{Ag}_{20}\left\{\mathrm{~S}_{2} \mathrm{P}\left(\mathrm{O}^{\mathrm{n}} \mathrm{Pr}\right)_{2}\right\}_{12}\right]$ (8b), where unlike in (8a), capping atom $\mathrm{A}$ is completely off the $\mathrm{C}_{3}$ axis. Color code: $\mathrm{Ag}$ purple and green, $\mathrm{S}$ yellow, $\mathrm{P}$ light blue. Reproduced with permission from ref. 34. Copyright 2016 Wiley-VCH. 

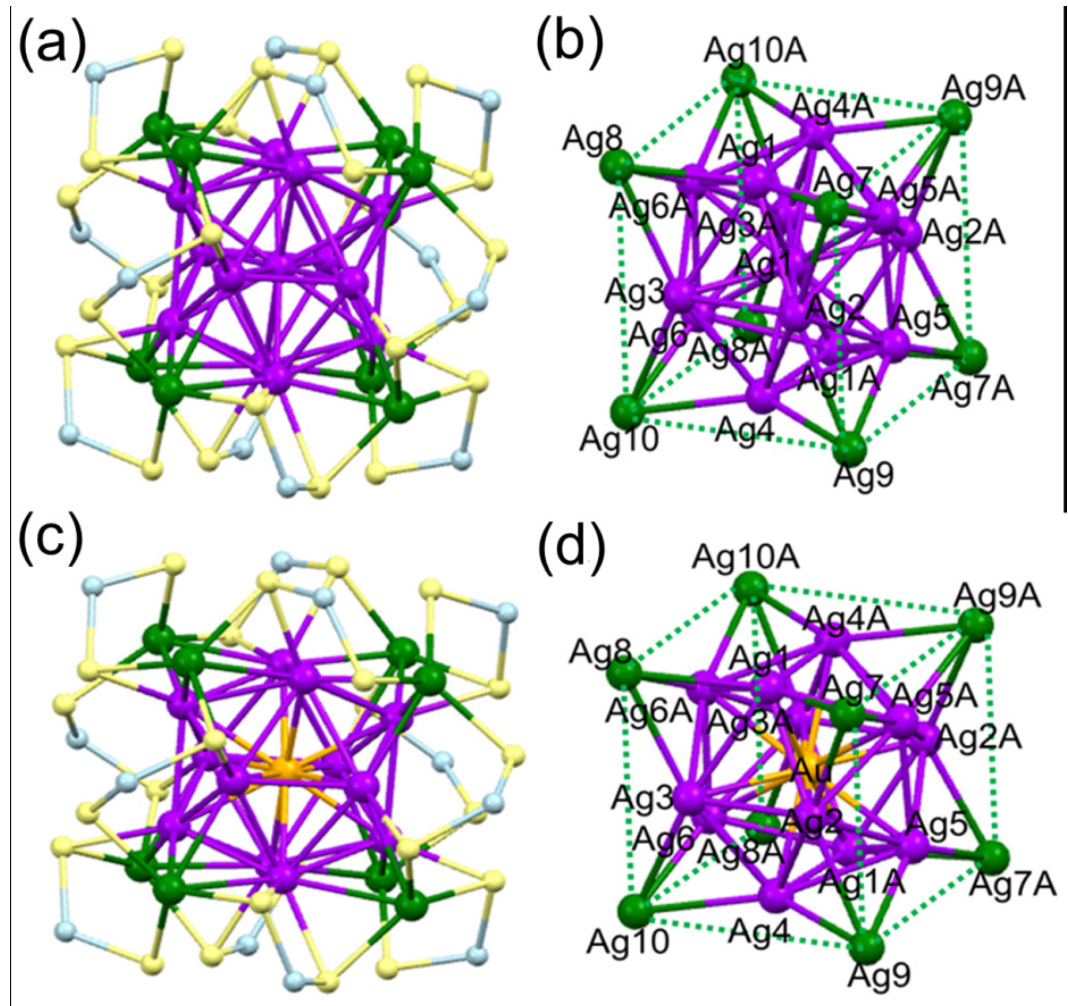

(d) $\quad$ Ag10A

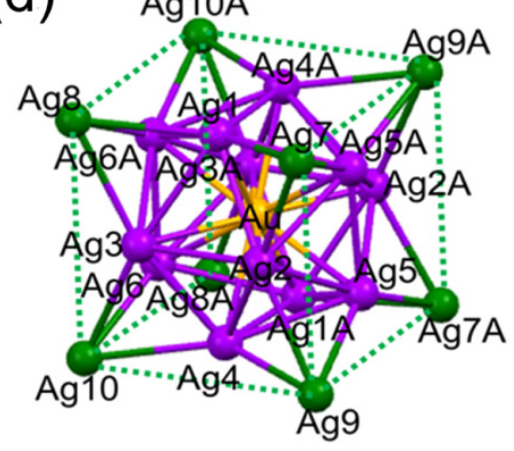

Figure 5 (a) Total structure of $\left[\mathrm{Ag}_{21}\left\{\mathrm{Se}_{2} \mathrm{P}(\mathrm{OEt})_{2}\right\}_{12}\right]^{+}$(11) with ethoxy groups omitted for clarity; (b) the $\mathrm{Ag}_{13}$ centered icosahedron engraved in an $\mathrm{Ag}_{8}$ cube; (c) total structure of $\left[\mathrm{AuAg}_{20}\left\{\mathrm{Se}_{2} \mathrm{P}(\mathrm{OEt})_{2}\right\}_{12}\right]^{+}$ (12) with ethoxy groups omitted for clarity; (d) the $\mathrm{Ag}_{8}$ cube encapsulating a centred icosahedral $\mathrm{Au} @ \mathrm{Ag}_{12}$ unit. Color code: Ag purple and green, Se light yellow, P light blue. Reproduced with permission from ref. 40. Copyright 2017 Wiley-VCH. 

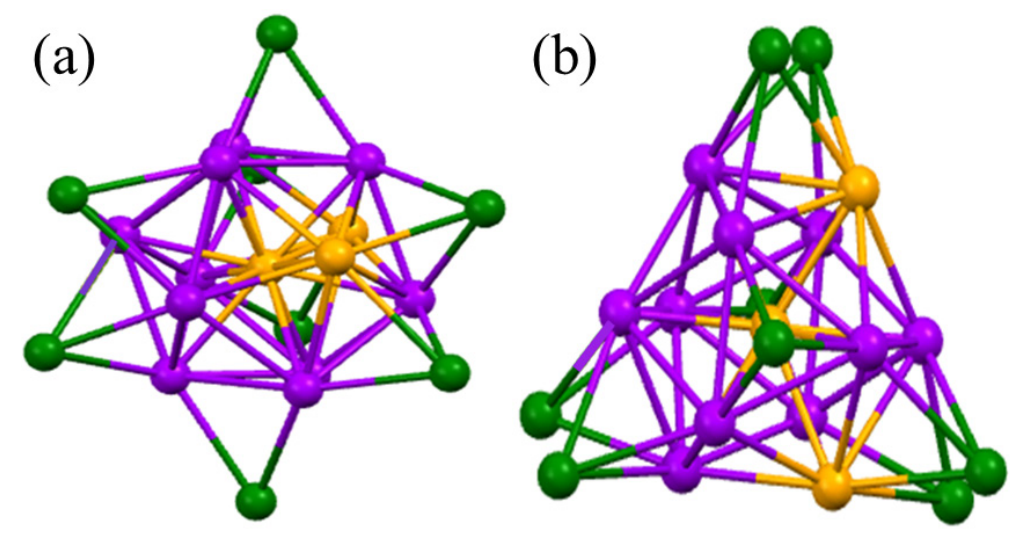

Figure 6. (a) Side view and (b) top view of the metal core in $\left[\mathrm{Au}_{3} \mathrm{Ag}_{18}\left\{\mathrm{Se}{ }_{2} \mathrm{P}\left(\mathrm{O}^{i} \mathrm{Pr}\right)_{2}\right\}_{12}\right]^{+}(\mathbf{1 3})$ with isopropoxy groups omitted for clarity. Color code: green, capping Ag; purple, icosahedral Ag; orange, Au. Reproduced with permission from ref. 41.Copyright 2018 Wiley-VCH.

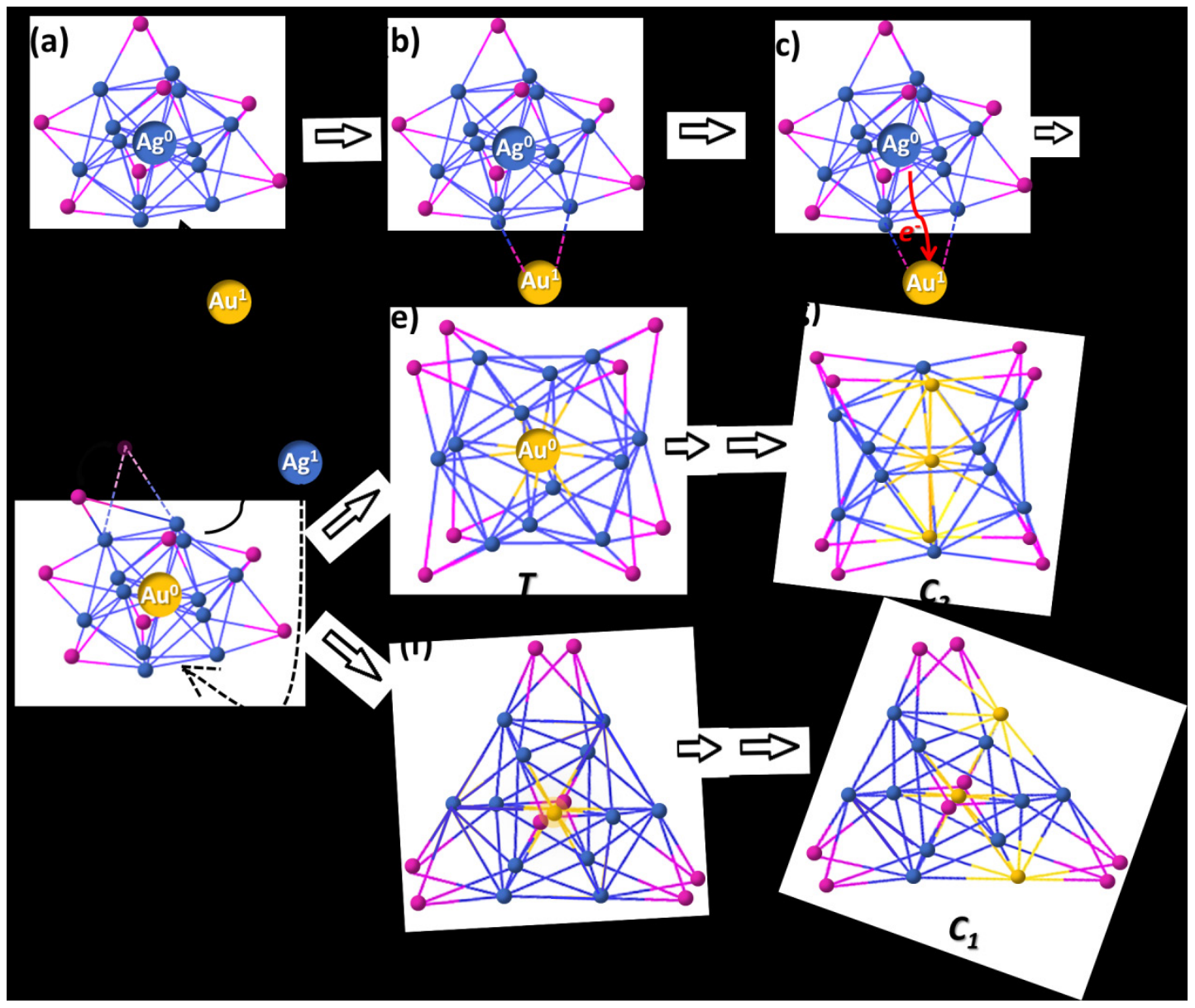

Figure 7. A proposed reaction mechanism of the doping $\left[\mathrm{Ag}_{20}\left\{\mathrm{Se}_{2} \mathrm{P}\left(\mathrm{O}^{\mathrm{i}} \mathrm{Pr}\right)_{2}\right\}_{12}\right]$ cluster with $\mathrm{Au}$. 


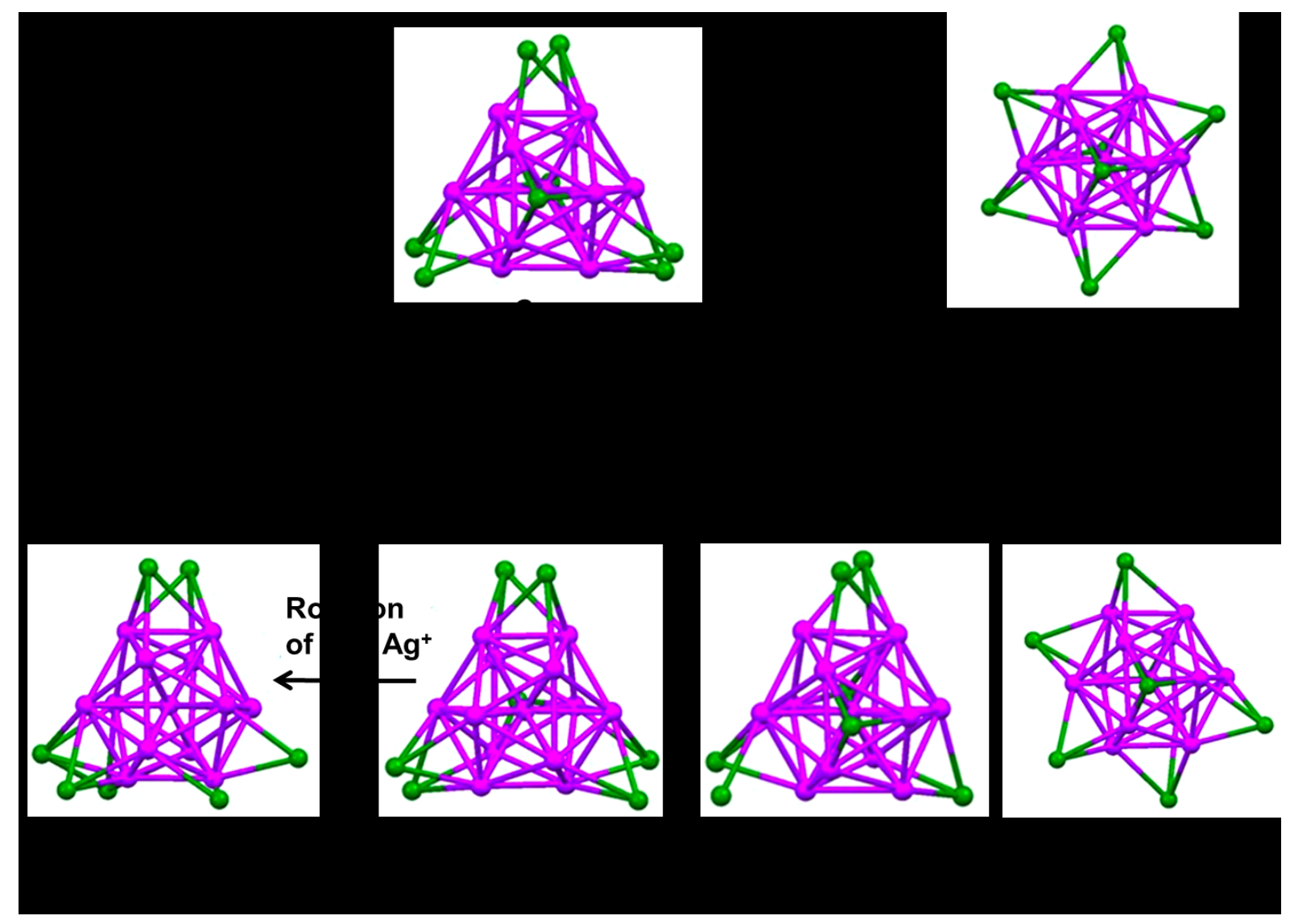

Figure 8. Structural relationships between $\mathrm{Ag}_{20}$ and $\mathrm{Ag}_{21}$ cores within the $\left[\mathrm{Ag}_{21}\left\{\mathrm{E}_{2} \mathrm{P}(\mathrm{OR})_{2}\right\}_{12}\right]^{+}$and $\left[\mathrm{Ag}_{20}\left\{\mathrm{E}_{2} \mathrm{P}(\mathrm{OR})_{2}\right\}_{12}\right]$ series and DFT-computed relative free energies computed for the $\left[\mathrm{Ag}_{21}\left(\mathrm{E}_{2} \mathrm{PH}_{2}\right)_{12}\right]^{+}$and $\left[\mathrm{Ag}_{20}\left(\mathrm{E}_{2} \mathrm{PH}_{2}\right)_{12}\right]$ models. 